\title{
A systematic umbrella review of the association of prescription drug insurance and cost-sharing with drug use, health services use, and health
}

\author{
G. Emmanuel Guindon ${ }^{1,2,3^{*}}$, Tooba Fatima', Sophiya Garasia ${ }^{1,2}$ and Kimia Khoee ${ }^{1}$
}

\begin{abstract}
Background: Increasing spending and use of prescription drugs pose an important challenge to governments that seek to expand health insurance coverage to improve population health while controlling public expenditures. Patient cost-sharing such as deductibles and coinsurance is widely used with aim to control healthcare expenditures without adversely affecting health.

Methods: We conducted a systematic umbrella review with a quality assessment of included studies to examine the association of prescription drug insurance and cost-sharing with drug use, health services use, and health. We searched five electronic bibliographic databases, hand-searched eight specialty journals and two working paper repositories, and examined references of relevant reviews. At least two reviewers independently screened the articles, extracted the characteristics, methods, and main results, and assessed the quality of each included study.

Results: We identified 38 reviews. We found consistent evidence that having drug insurance and lower cost-sharing among the insured were associated with increased drug use while the lack or loss of drug insurance and higher drug cost-sharing were associated with decreased drug use. We also found consistent evidence that the poor, the chronically ill, seniors and children were similarly responsive to changes in insurance and cost-sharing. We found that drug insurance and lower drug cost-sharing were associated with lower healthcare services utilization including emergency room visits, hospitalizations, and outpatient visits. We did not find consistent evidence of an association between drug insurance or cost-sharing and health. Lastly, we did not find any evidence that the association between drug insurance or cost-sharing and drug use, health services use or health differed by socioeconomic status, health status, age or sex.

Conclusions: Given that the poor or near-poor often report substantially lower drug insurance coverage, universal pharmacare would likely increase drug use among lower-income populations relative to higher-income populations. On net, it is probable that health services use could decrease with universal pharmacare among those who gain drug insurance. Such cross-price effects of extending drug coverage should be included in costing simulations.
\end{abstract}

Keywords: Insurance, Cost-sharing, Copayment, Prescription drug, Review

${ }^{*}$ Correspondence: emmanuel.guindon@mcmaster.ca

${ }^{1}$ Centre for Health Economics and Policy Analysis, McMaster University,

Room 229, 1280 Main Street West, Hamilton, ON L8S 4K1, Canada

Full list of author information is available at the end of the article

\section{Background}

As the US strives to reduce its uninsurance rate, it faces an intensifying challenge of increasing out-of-pocket costs in employer-sponsored health insurance [1, 2]. 
All the while Canada is debating how best to provide drug insurance to all its residents [3]. Canada is often cited as the only high-income country with universal health insurance coverage lacking universal coverage for prescription drugs [4]. Increasing spending and use of prescription drugs pose an important challenge to governments that seek to expand health insurance coverage to improve population health while controlling public expenditures. Patient cost-sharing such as deductibles and coinsurance is widely used with aim to control healthcare expenditures without adversely affecting health [5].

Since the seminal RAND Health Insurance Experiment [6], numerous studies have examined, at various times and across diverse settings, the impact of health insurance generally, and drug insurance in particular, on utilization and health outcomes. For example, in the US, the introduction of Medicare Part D in 2003 and the Affordable Care Act in 2010 have generated a wealth of new research $[7,8]$. Likewise in Canada, the prospect of universal pharmacare and important changes to provincial drug programs such as the 1997 public/private prescription drug program that covered all Québec residents and British Columbia's adoption of income-based Pharmacare in 2003 in place of an age-based drug benefits program have resulted in an abundance of new analyses $[3,9,10]$. Countless reviews have examined the impact of prescription drug insurance and drug cost-sharing on an array of outcomes such as drug use, health services use, and health, in varied settings and among heterogenous populations. To our knowledge, there has not been an attempt to assess the quality and synthesize evidence from existing reviews. In addition to identifying the strength/credibility of combined associations from reviews to present an objective and comprehensive synthesis of the evidence, such a review of reviews can identify knowledge gaps in the literature, provide useful guidance for future reviews, and have greater implications for policy and practice.

We conducted a systematic umbrella review in order to provide a closer examination of what policy introductions of prescription drug coverage (with and without cost-sharing) would mean for both individuals and governments financing this coverage. We examined reviews that studied the association between having prescription drug coverage (primary and supplementary), as well as varying types and levels of cost-sharing, and:

1. the utilization of prescription drugs (i.e., own-price effects on drug use);

2. the utilization of healthcare services (i.e., cross-price effects on the use of health services such as physician, emergency department, and inpatient services);
3. health outcomes (i.e., own-price effects on health outcomes);

We also examined the degree to which the associations identified in 1-3 above differed across levels of socioeconomic status (SES, e.g., income, education), populations of differing health status such as the chronically ill, age, and sex.

\section{Methods}

A review protocol was prepared in advance and registered with PROSPERO (CRD42017052018). We searched five electronic bibliographic databases: MEDLINE, Embase, Scopus, EconLit, and Health Systems Evidence. Grey literature was searched via the New York Academy of Medicine Grey Literature Report, Open Grey, Google, and Google Scholar. Eight specialty journals (BMC Health Services Research, Health Affairs, Healthcare Policy, Health Economics, Journal of Health Economics, Health Economics, Policy and Law, Health Services Research, and Medical Care Research and Review) and two working paper repositories (RePEc, Research Papers in Economics and the National Bureau of Economic Research working paper series) were 'hand-searched.' We examined references of included reviews and of reviews that cited key studies using Web of Science and Google Scholar. The database search was last updated on September 15, 2020. At least two reviewers, using distillerSR, screened titles and abstracts of citations to determine relevance, then full text if relevance was unclear.

\section{Inclusion and exclusion criteria}

Types of studies: all reviews (e.g., narrative, rapid, scoping, systematic, meta-analysis, meta-regression). Types of interventions: (1) insurance: all studies that examined the expansion of prescription drug insurance, irrespective of the insurance provider (e.g., government, employers, professional associations) and studies that examined partial or full-delisting of prescription drugs from insurance coverage; (2) cost-sharing: all studies that examined any form of direct patient payment for prescription drugs including, but not limited to, fixed copayment, coinsurance, ceilings, and caps. Types of outcomes: all reviews that included as an outcome any of drug utilization, health services utilization, or health outcomes. Time period: all reviews published since January 2000. Languages: we included only studies written in English and French. We excluded reviews that focused solely on lowand middle-income countries.

\section{Quality assessment and data extraction}

We used the Assessment of Multiple Systematic Reviews (AMSTAR) measurement tool as a methodological guide 
[11]. Although AMSTAR's focus is primarily on the reporting quality of reviews, we paid particular attention to the quality assessment conducted in each review. At least two reviewers independently extracted detailed study characteristics for each included review using a standardized form, including all AMSTAR 2 items (see Additional file 1). The following study characteristics were extracted, where possible: citation, type of review, population investigated, research question, outcomes studied, whether there was an 'a priori design' and duplicate study selection and data extraction, the comprehensiveness of the search including if grey literature was searched, year/month of last search, whether the keywords/search strategy were reported, total number of studies included, total number of studies included that focused on drug insurance and/or cost-sharing, whether a list of included and excluded studies were provided, whether the characteristics of the included studies were provided, whether the scientific quality of the included studies was assessed, documented, and used appropriately in formulating conclusions, whether the methods used to combine the findings of studies were appropriate, whether the likelihood of publication bias was assessed, whether funding and competing of interests were clearly reported, key results for each of drug use, healthcare services utilization, and health, and reviews' conclusion (as stated by the authors). In assessing the quality of the included studies, we paid particular attention to the following components: 'a priori' design; duplicate study selection and data extraction; systematic search strategy; presentation of characteristics of included studies and list of excluded studies and reasons for exclusion; quality assessment of included studies; and the generalizability of the findings. We did not compute total scores as empirical evidence does not support their use [12-14]. We created summary tables, organized by outcome and subgroup, using our completed standardized forms. For each study, we highlighted the direction and magnitude of the associations. In our descriptive table, we present the study citations, research question, outcomes studied, study selection and extraction process, quality assessment, and limitations/risk of bias. Lastly, given the current policy debate surrounding universal pharmacare in Canada, we also reported the total number of Canadian studies included that focused on drug insurance and/or cost-sharing [3].

\section{Results}

The database search produced 5567 records after the removal of duplicate citations, from which 5261 were excluded based on the title/abstract screen and 268 were subsequently removed after a full-text screen, yielding 38 reviews that met all inclusion criteria (Fig. 1). Selected study characteristics and our assessment of study's limitations are presented in Table 1. Detailed characteristics of included studies are presented in the Additional file 1. Of 38 reviews, 16 focused on the general population of which eight also commented on subgroups (e.g., seniors, the poor, and chronically ill), nine focused on seniors (most often on the US Medicare population), and 11 focused on the poor and/or chronically ill. A further two reviews examined drug insurance and cost-sharing among Canadians and one review examined publicly insured populations. Most included reviews were narrative reviews. We included six meta-analyses and one meta-regression. A list of excluded studies and reasons for exclusion is provided in the Additional file 1. We present a synthesis of results in Table 2 and more detailed findings for each reviews in Tables 3, 4, 5, 6, 7, and 8 .

\section{Associations of prescription drug insurance and cost-sharing with drug utilization}

Examining the 20 reviews that investigated, with a focus on the general population, the association between having prescription drug coverage or varying levels of cost-sharing on drug use, there was a clear inverse association, but the magnitude of the association was unclear (Tables 2 and 3). Across the literature, the outcomes were reported in elasticities, changes in drug use, and changes in medication adherence, with reviews published between 2004 and 2019. Reviews assessing medication adherence generally found that the absence of prescription drug insurance, or having copayments, reduced medication adherence $[21,32,36,41,46]$ with specific estimates ranging as low as a $0.4 \%$ decrease in adherence for each dollar increase in copays, and an average reduction of $3 \%$ after 1 year of copayment reductions [32]. Another review reported that publicly insured patients who were required to pay copays for their prescription medicines had $11 \%$ higher odds of reporting nonadherence relative to those who faced no copayments [36]. However, not all associations were statistically significant, with variations in adherence reported depending on the drug class. Reviews reporting on drug use also generally found consistent results, reporting that increasing costsharing or not having drug insurance decreased drug use, but with varying impacts by drug class or type, and some not reporting clear effect sizes or very small to moderate impacts [16, 26, 27, 37, 39, 40, 51]. Own-price elasticities reported in seven older reviews, published in 2011 or earlier, generally found that the demand for prescription drugs was inelastic, with most estimates ranging from -0.2 to -0.6 depending on the drug class and essentiality, suggesting that a $10 \%$ increase in price resulted in a 2 to $6 \%$ decrease in use $[19,22-25,29,30]$. 


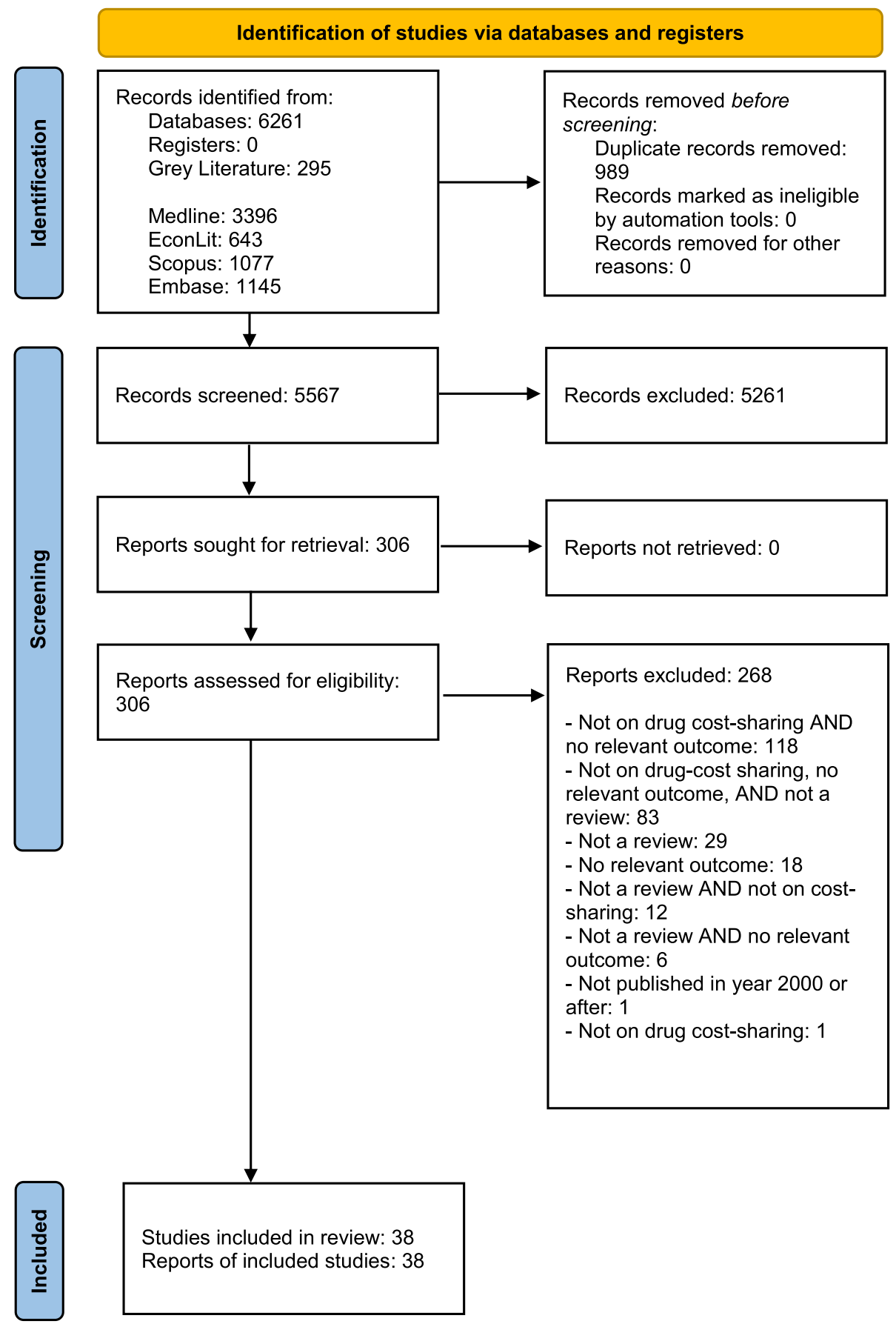

Fig. 1 PRISMA 2020 flow diagram for new systematic reviews which included searches of databases and registers only

Differences between subgroups: SES, health status, age, and sex/gender

These results varied when assessing vulnerable population subgroups including the elderly, children, the poor, and the chronically ill (Tables 2 and 4). We identified two reviews that focused specifically on low-income groups
$[17,44]$ and six that generally commented on low-SES populations [23-25, 27, 29, 37]. One older review focusing on low-income populations reported price elasticities ranging from -0.3 and -0.5 and argued there was unequivocal evidence that increasing cost-sharing decreased drug use among the poor [17]. This conclusion 


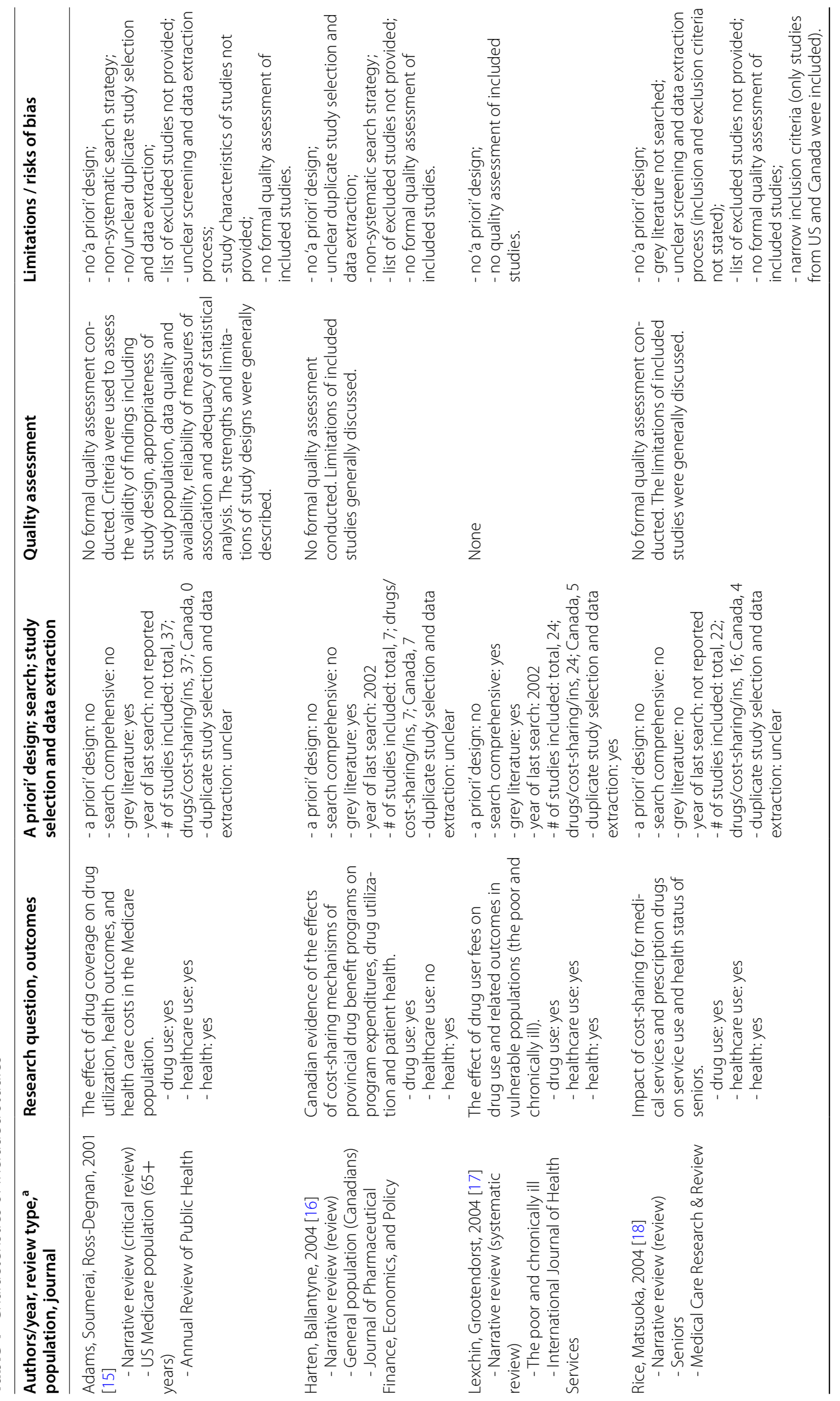



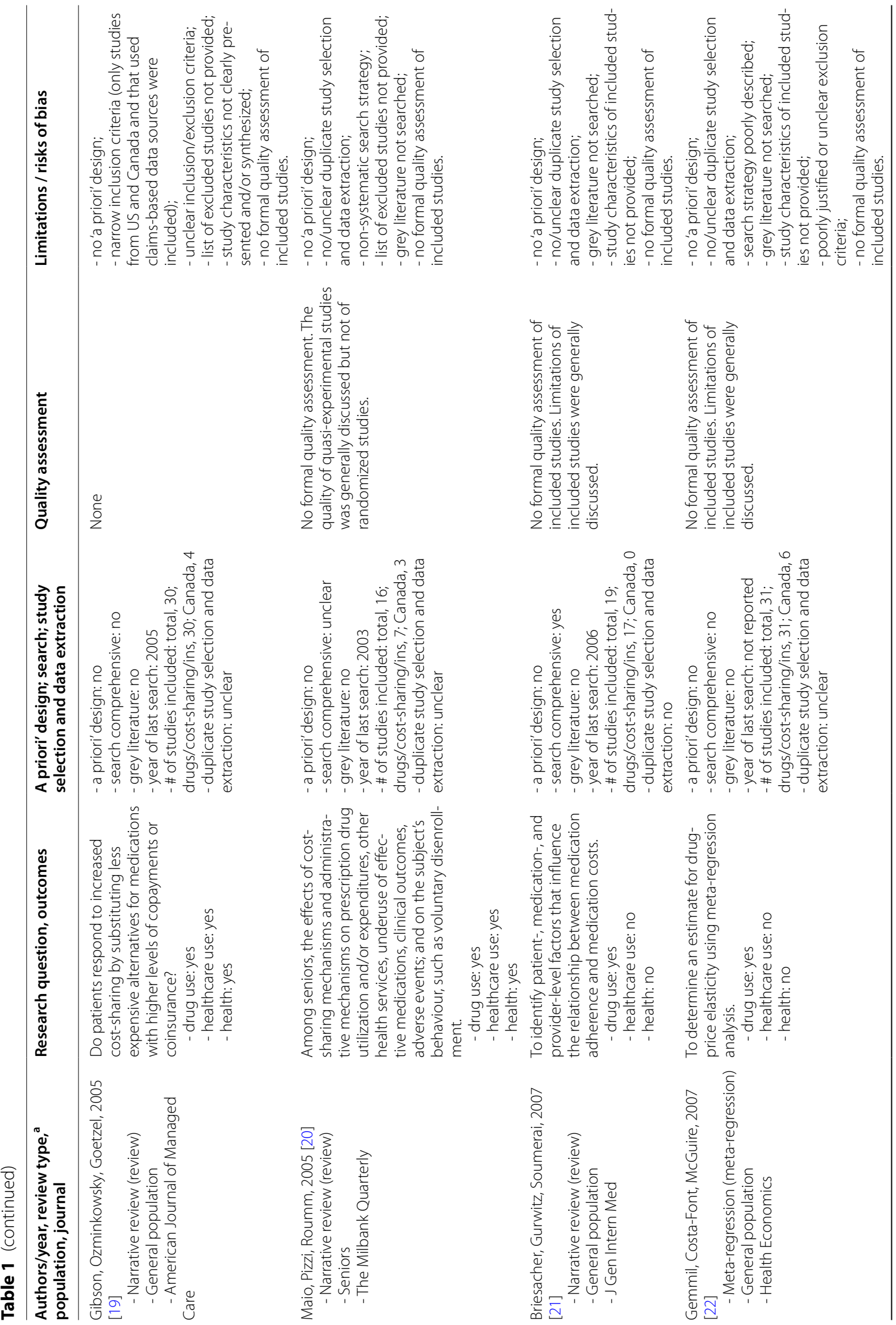


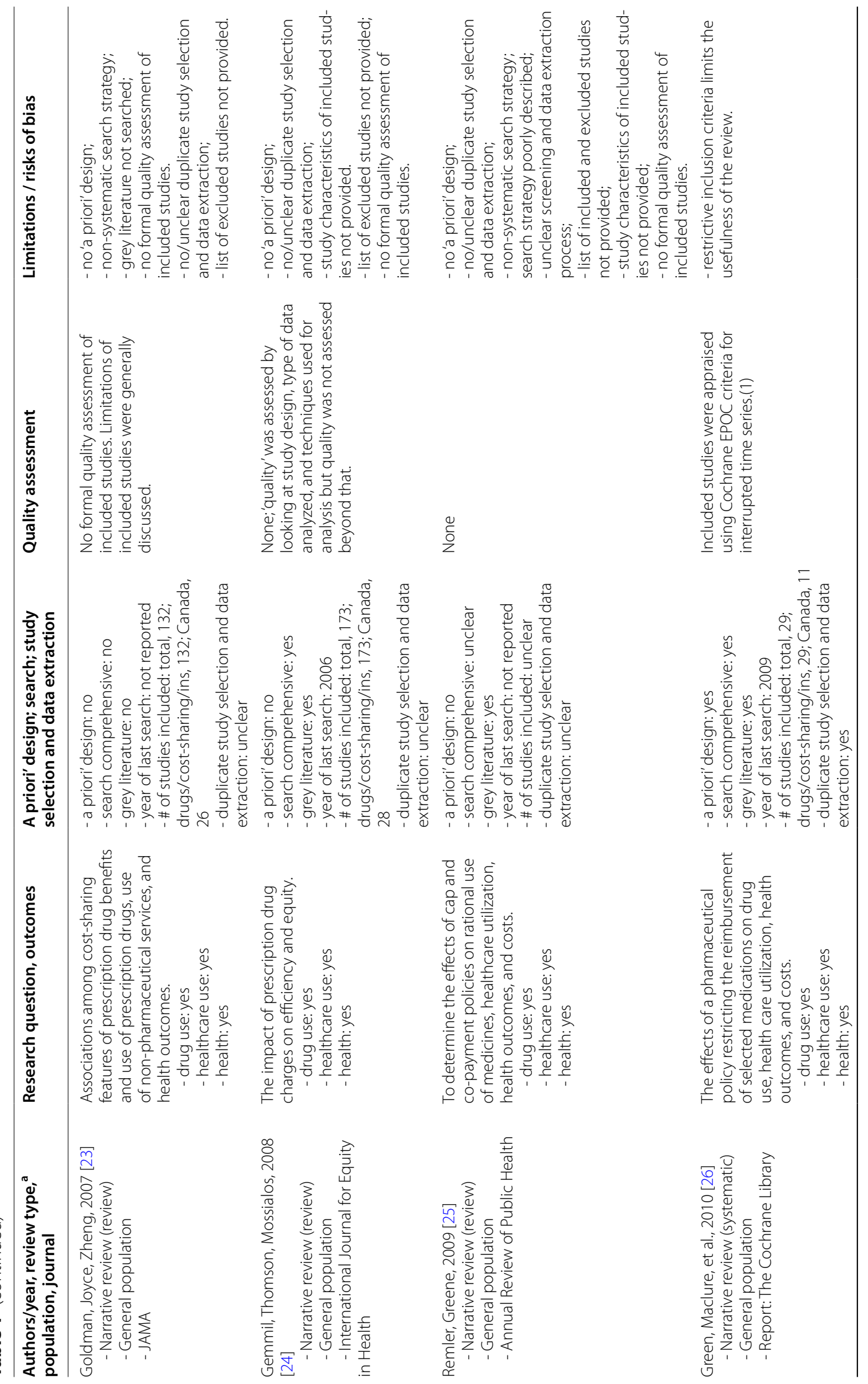




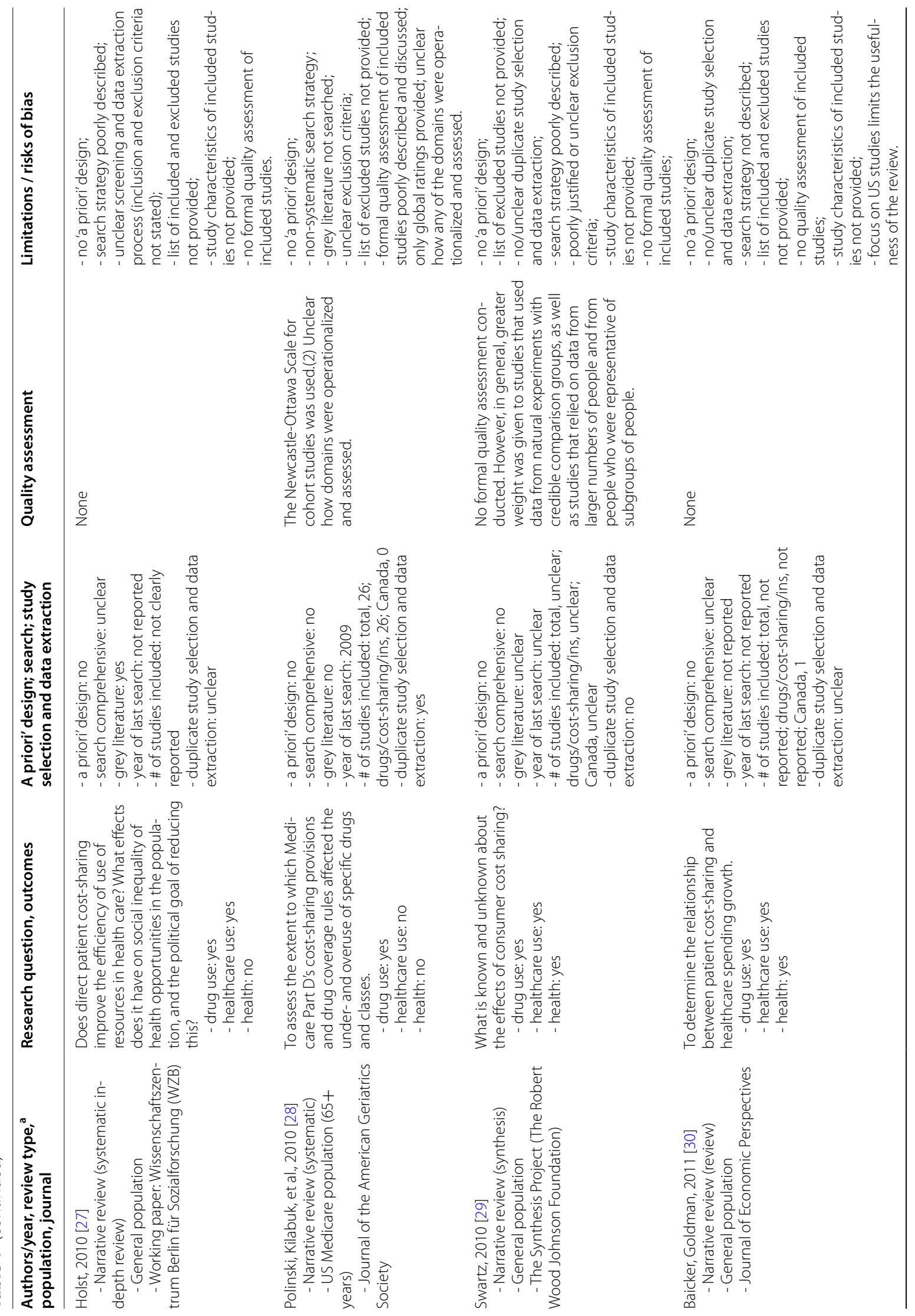




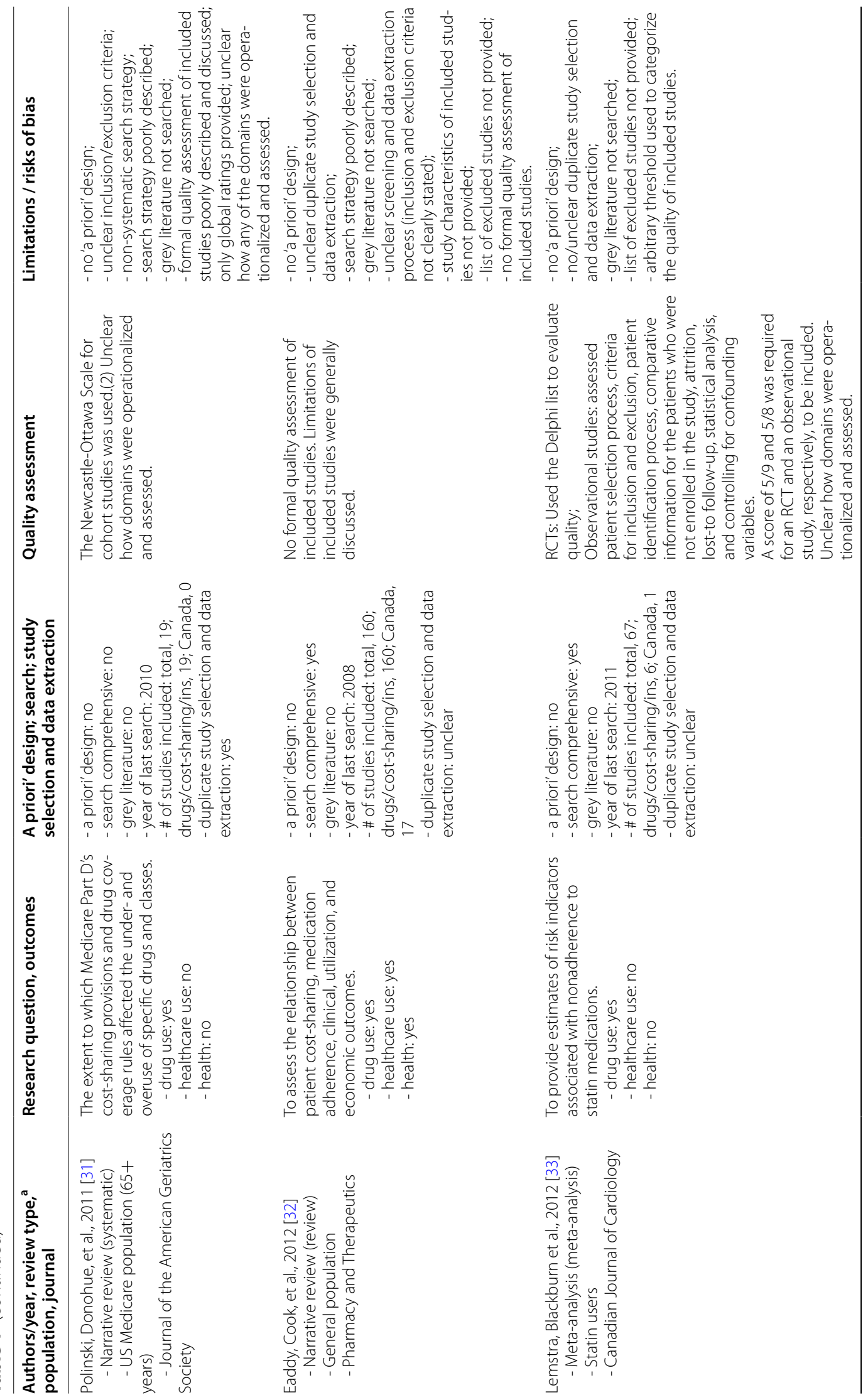




\begin{tabular}{|c|c|c|c|c|}
\hline & 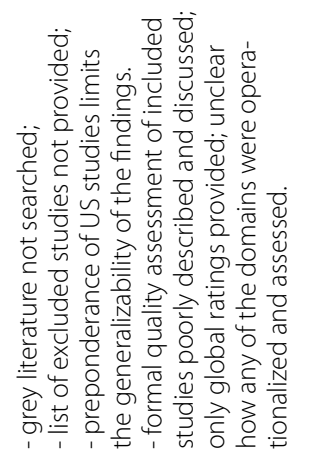 & 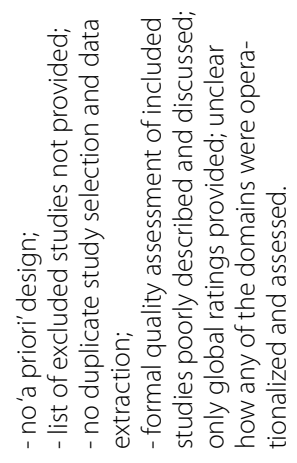 & 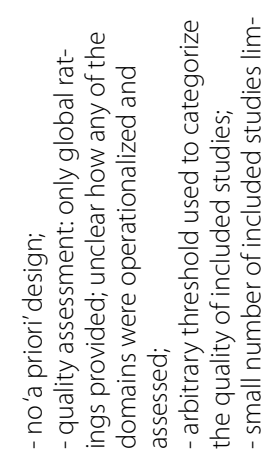 & 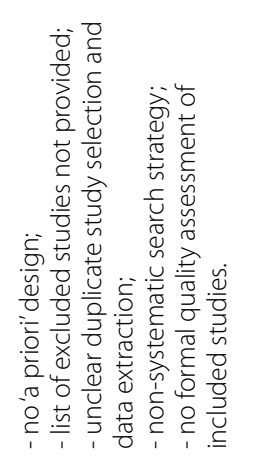 \\
\hline & 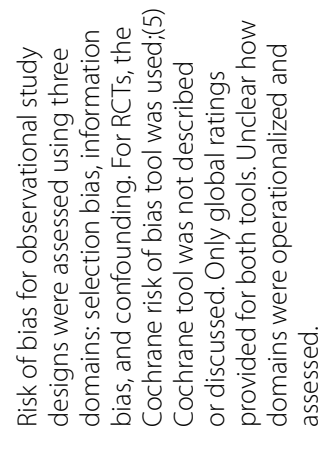 & 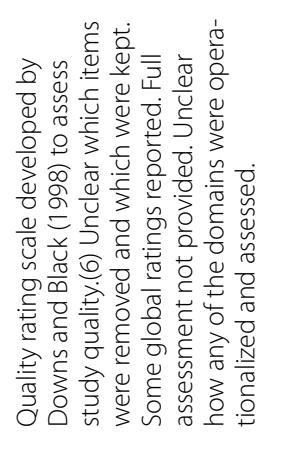 & 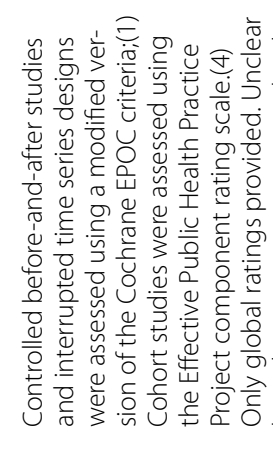 & \\
\hline 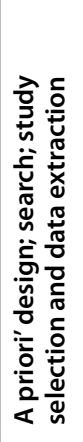 & 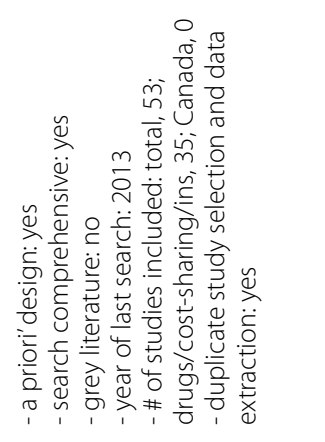 & 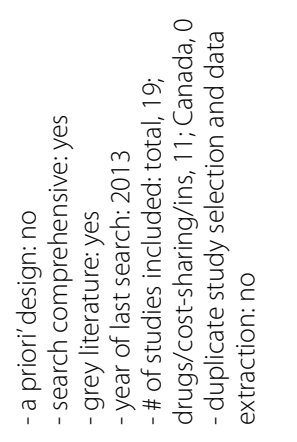 & 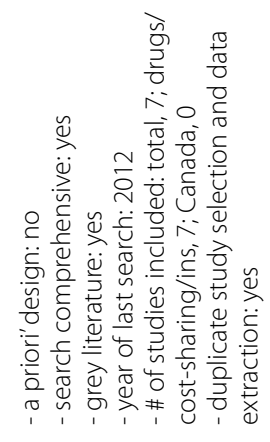 & 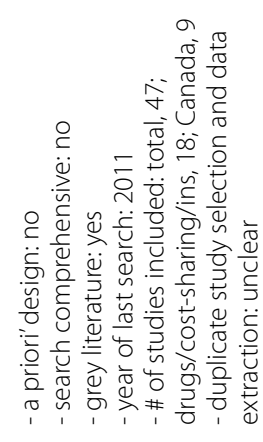 \\
\hline & 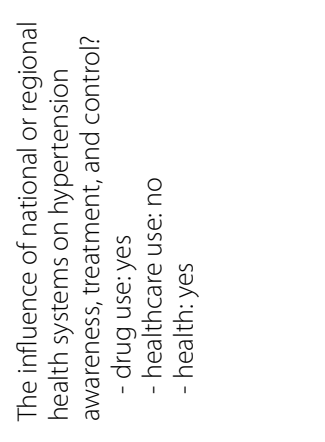 & 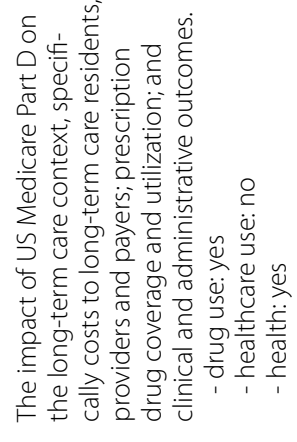 & 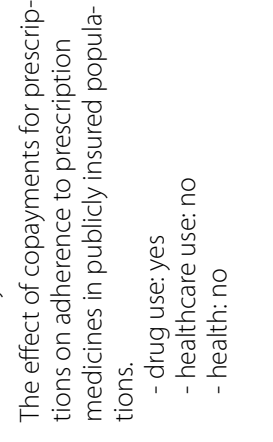 & 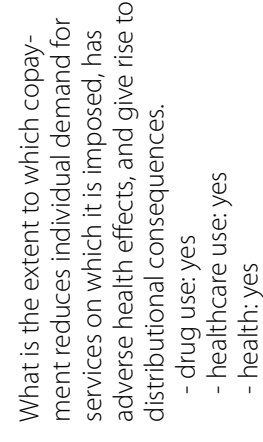 \\
\hline 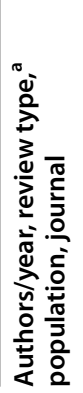 & 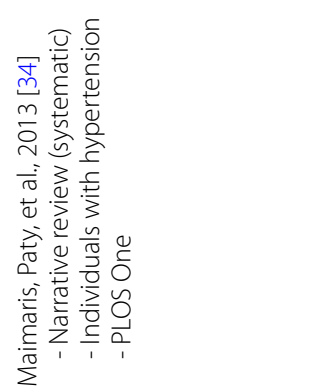 & 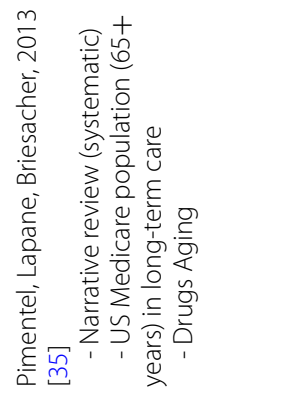 & 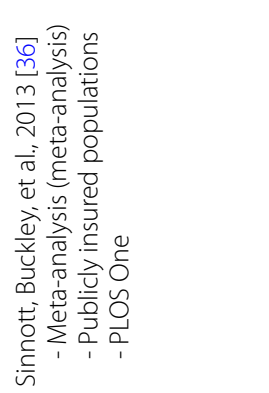 & 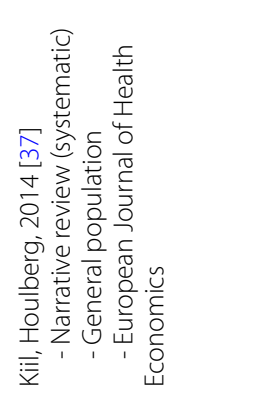 \\
\hline
\end{tabular}




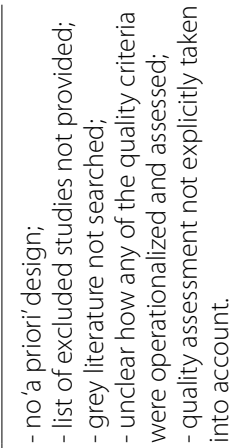
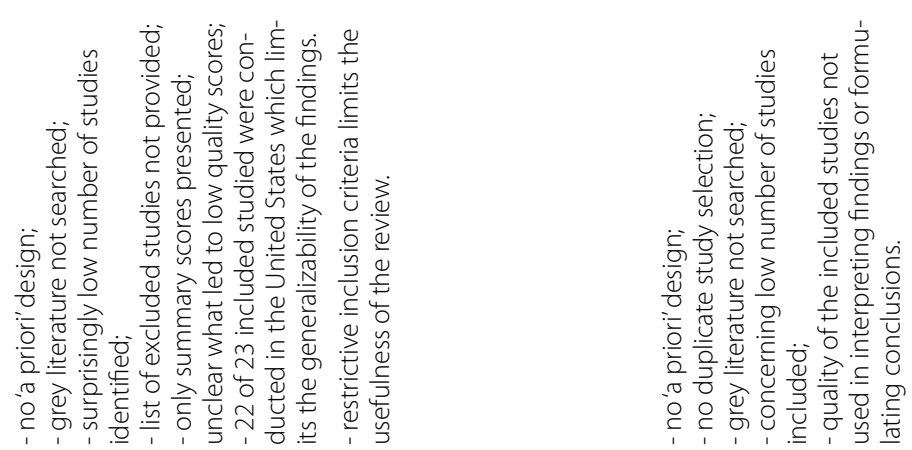

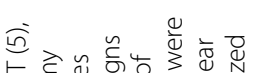

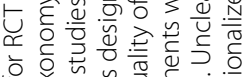

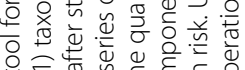

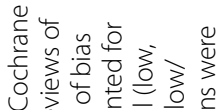

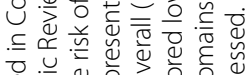

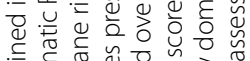

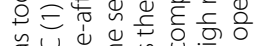<smiles></smiles>

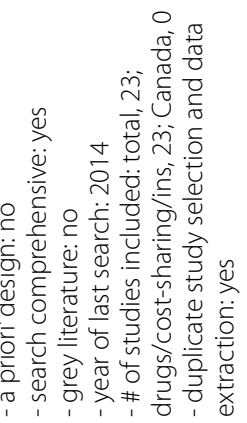

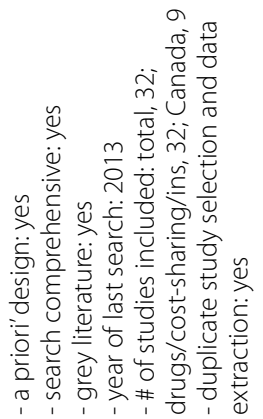

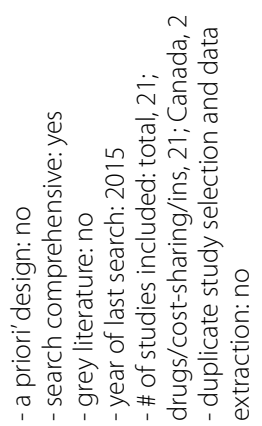

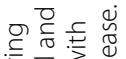

$\circ$ 원

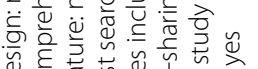

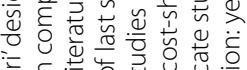

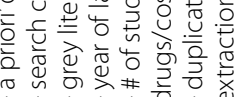

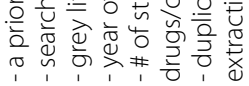

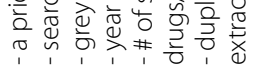

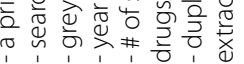

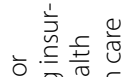

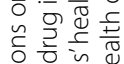

든. 든.

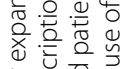

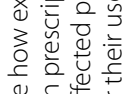

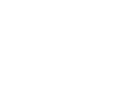

है.

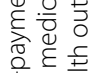

高皆

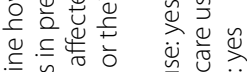

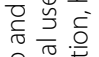

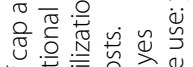

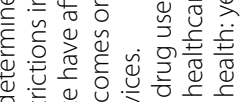

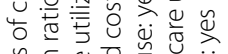

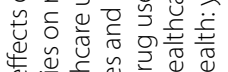

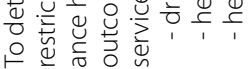

类.

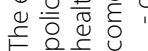
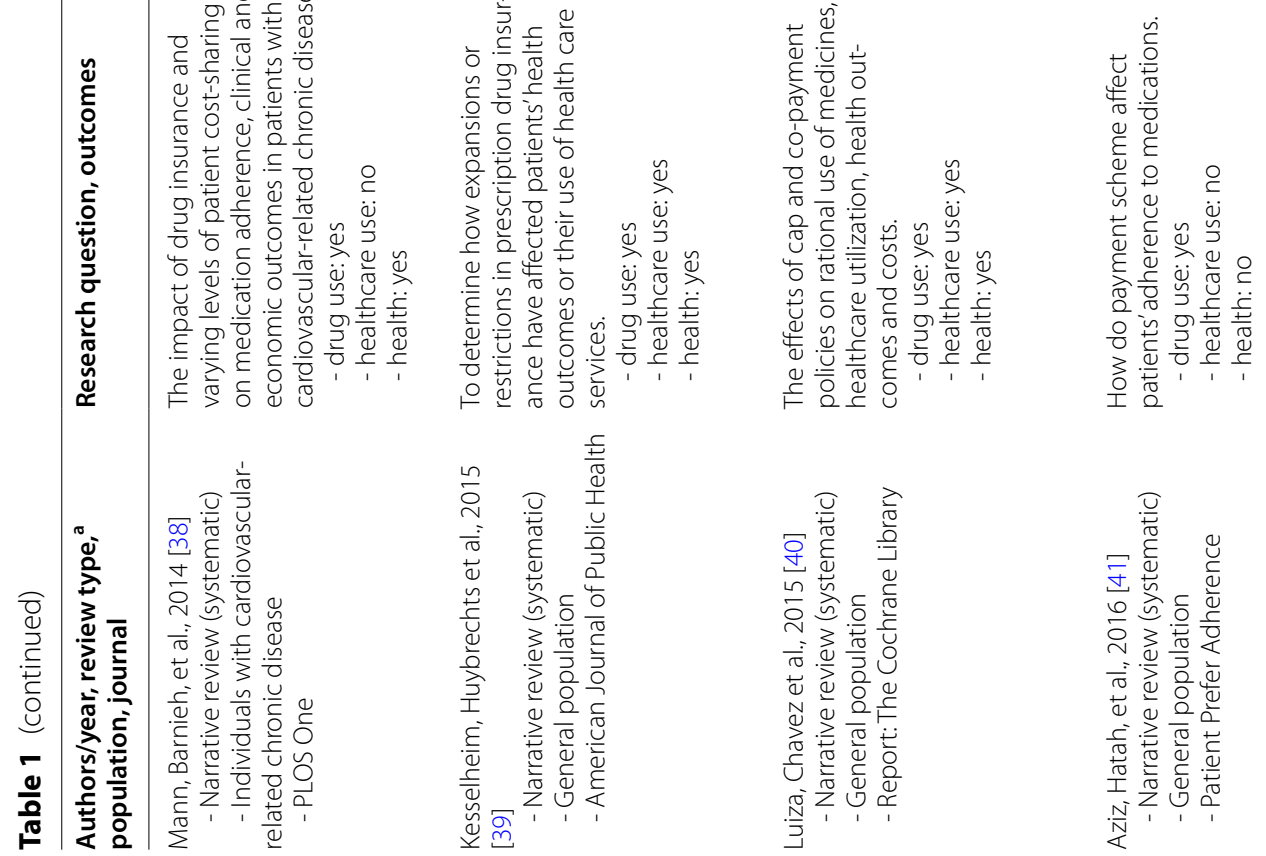


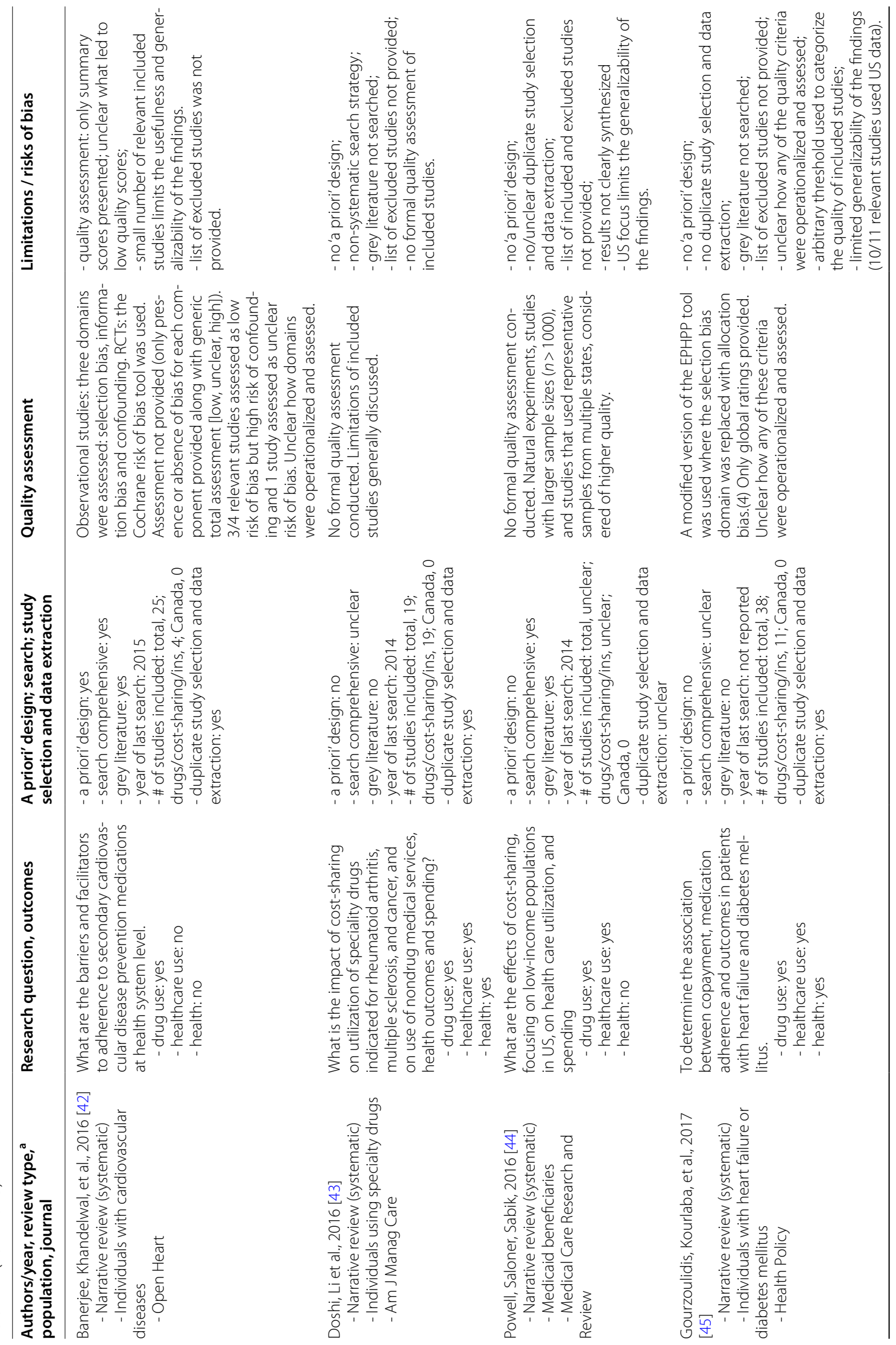




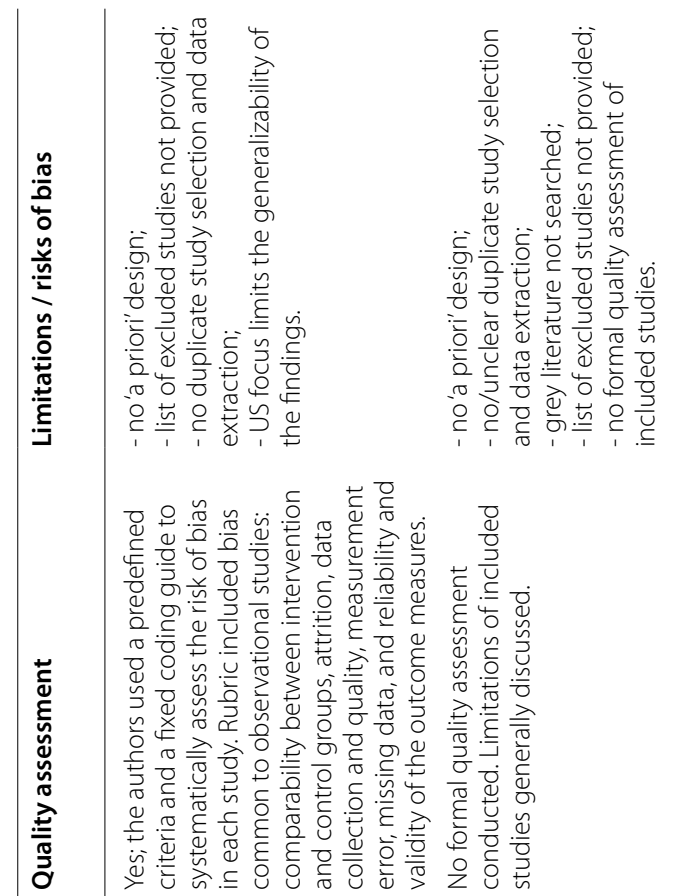

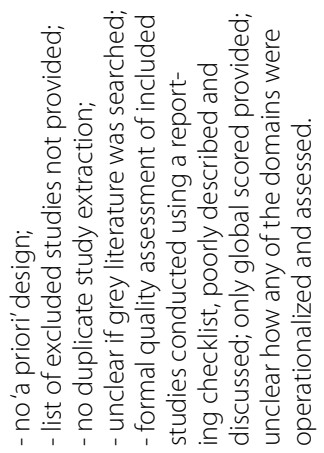

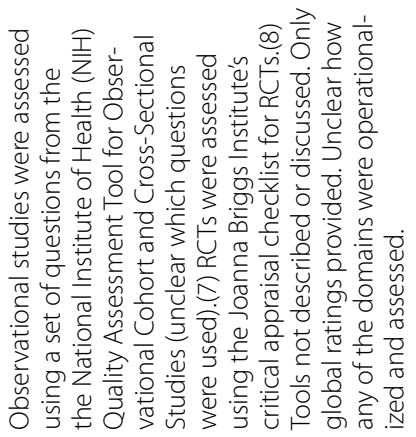

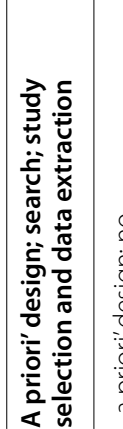

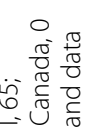

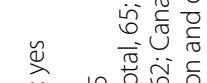

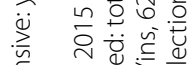

워

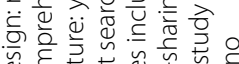

论

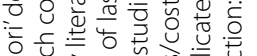

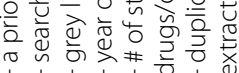

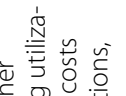

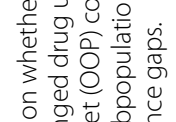

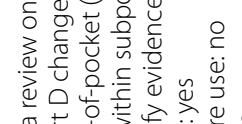

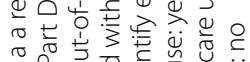

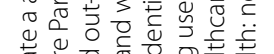

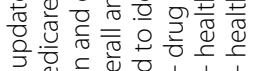

คำ

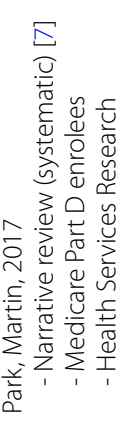

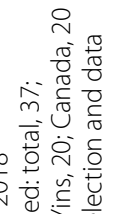

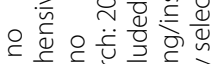

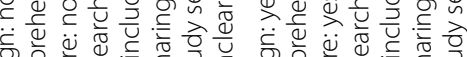

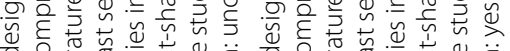

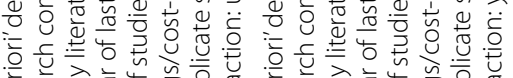

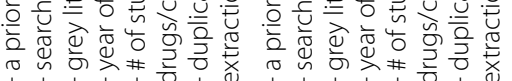
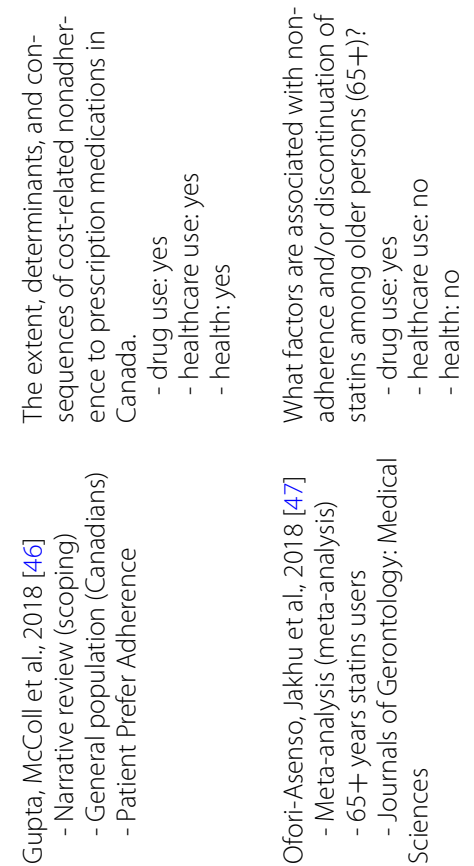

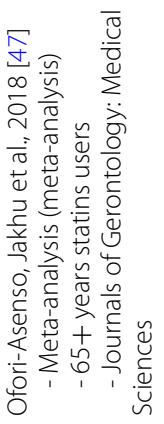

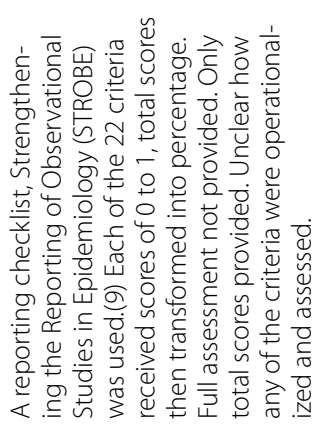
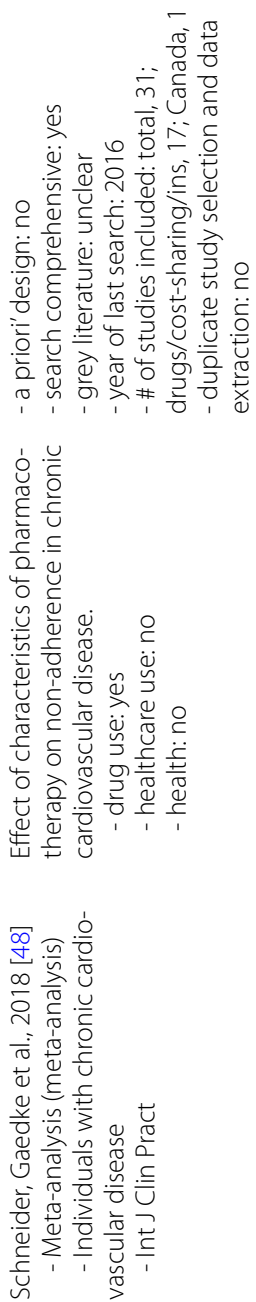


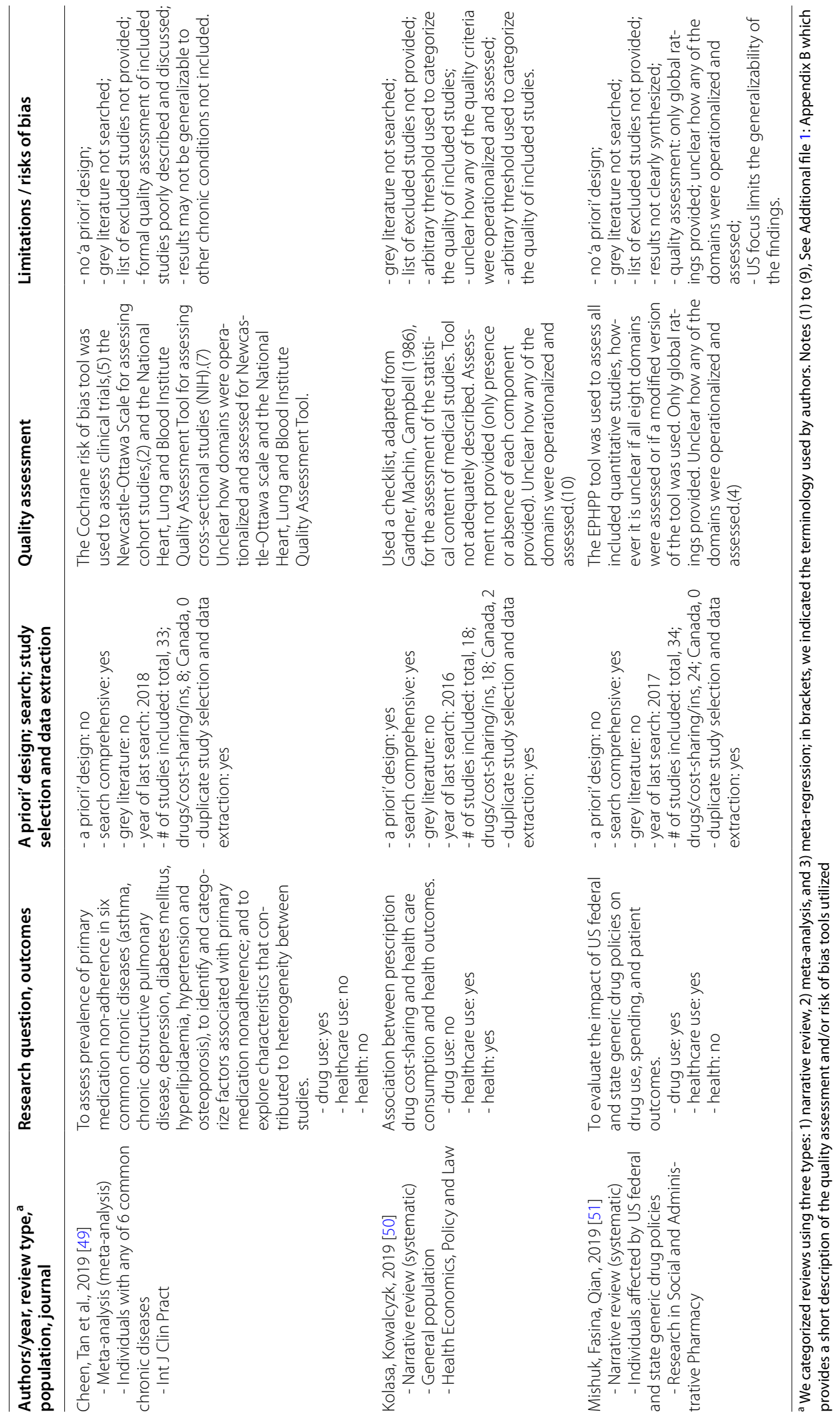


Table 2 Summary of results: association between prescription drug insurance/cost-sharing and drug use, health services use, and health

\section{Drug use: general population}

Lack of insurance and higher cost-sharing were associated with lower drug use $[19,22-24,27,29,30,37,39,40,51]$;

- Own-price $n \approx-0.1$ to $-0.6[29]$;

- Own-price $\eta \approx-0.6$ to -0.8 ; based on aggregate data [24];

- Own-price $\eta \approx-0.2$ to -0.6 ; based on individual/household data [24];

- Own-price $n \approx-0.2$ to $-0.6[23,30]$;

- Own-price $n \approx-0.2$ [22];

- Own-price $\eta \approx-0.1$ to -0.4 [19];

Restriction to reimbursement was associated with decreased drug use, either immediately after policy change or long-term [26];

Among Canadians, the introduction of or increases in drug cost-sharing was associated with either no change or lower use (essential and non-essential) [16]; The magnitude of association between cost-sharing and drug use depended on drug class, [23, 27, 30, 51] condition of patients, [23] and patient population [37];

Lack of drug insurance and higher cost-sharing were associated with lower medication adherence and a higher risk of cost-related nonadherence [19, 21, 32, $36,41,46,51]$;

- Overall, a \$10 increase was associated with a 3.8\% decrease in adherence [32];

- Publicly insured patients with copayments had higher odds of reporting nonadherence relative to those without copayments [36];

Duration of coverage and type of coverage modified the magnitude of the association between cost-sharing and adherence [21];

Drug insurance restrictions were associated with lower drug use and adherence [39];

Essential drugs:

- With increased cost-sharing, both essential and non-essential drug use was decreased but the decrease was larger for nonessential drugs [29];

- Mixed evidence that higher cost-sharing was associated with lower use of essential drugs, relative to nonessential; reductions in the use of non-essential drugs were usually slightly larger [23, 25];

Drug type: generic drugs, preferred brand-name drugs, over-the-counter drugs:

- Limited evidence that increased generic-brand cost-sharing differential was associated with changes in patterns of drug use [19];

- Limited evidence that increased cost-sharing for prescription drugs was associated with higher use of over-the-counter drugs [19];

- Increases in drug cost-sharing for non-preferred brand-name drugs was associated with lower use of non-preferred brand-name drugs and higher use of preferred brand-name drugs [19];

- Statin users required to make a copayment were more likely than others to be nonadherent [17];

- Among statin users $\geq 65$ years, higher copayment/cost (not necessarily solely drug cost-sharing) increased the likelihood of nonadherence and discontinuation [47].

\section{Drug use: older adults, seniors}

Among older adults, lack of insurance and higher cost-sharing were associated with lower drug use, increased nonadherence and discontinuation [24, 27, 29, 47];

Older people were not found to be more sensitive to price than the general population [24];

- Own-price $\eta$, older adults $\approx-0.1$ to $-0.6[24]$

In the US Medicare population, drug insurance was associated with higher drug use and decreased a risk of cost-related nonadherence [15, 21];

- The inception of Medicare Part D was associated with an increase in drug use (6 to 13\%) [23, 31];

- Entry into Medicare Part D coverage gaps was associated with lower drug use (9 to 16\%) [31];

- Among US Medicare population in long-term care, drug insurance was associated with lower use of drugs that carry safety concerns, but overall drug utilization may have been unaffected [35];

Among seniors, there was mixed evidence that higher cost-sharing was associated with lower drug use [20];

The magnitude of association between cost-sharing and drug use depended on drug class, [15, 28] condition of patients, [15] and, patient population [31];

Essential drugs: Among seniors, higher cost-sharing was associated with lower use of essential drugs [15, 18, 28];

Generic drugs: Entry into Medicare Part D coverage gaps was associated with increased use of generic drugs $(20 \%)[7,28,51]$.

\section{Drug use: socioeconomic status, chronically ill}

Among the poor and chronically ill, higher cost-sharing was associated with lower drug use [17, 23, 27];

- Own-price $\eta$, poor $\approx-0.05$ to -0.4 ; based on aggregate data [24];

- Own-price $\eta$, poor $\approx-0.03$ to -0.2 ; based on individual/household data [24];

- Own-price $\eta$, poor/chronically ill $\approx-0.3$ to -0.5 [17];

Vulnerable populations were more responsive to cost-sharing than non-vulnerable population [37]; 
Table 2 (continued)

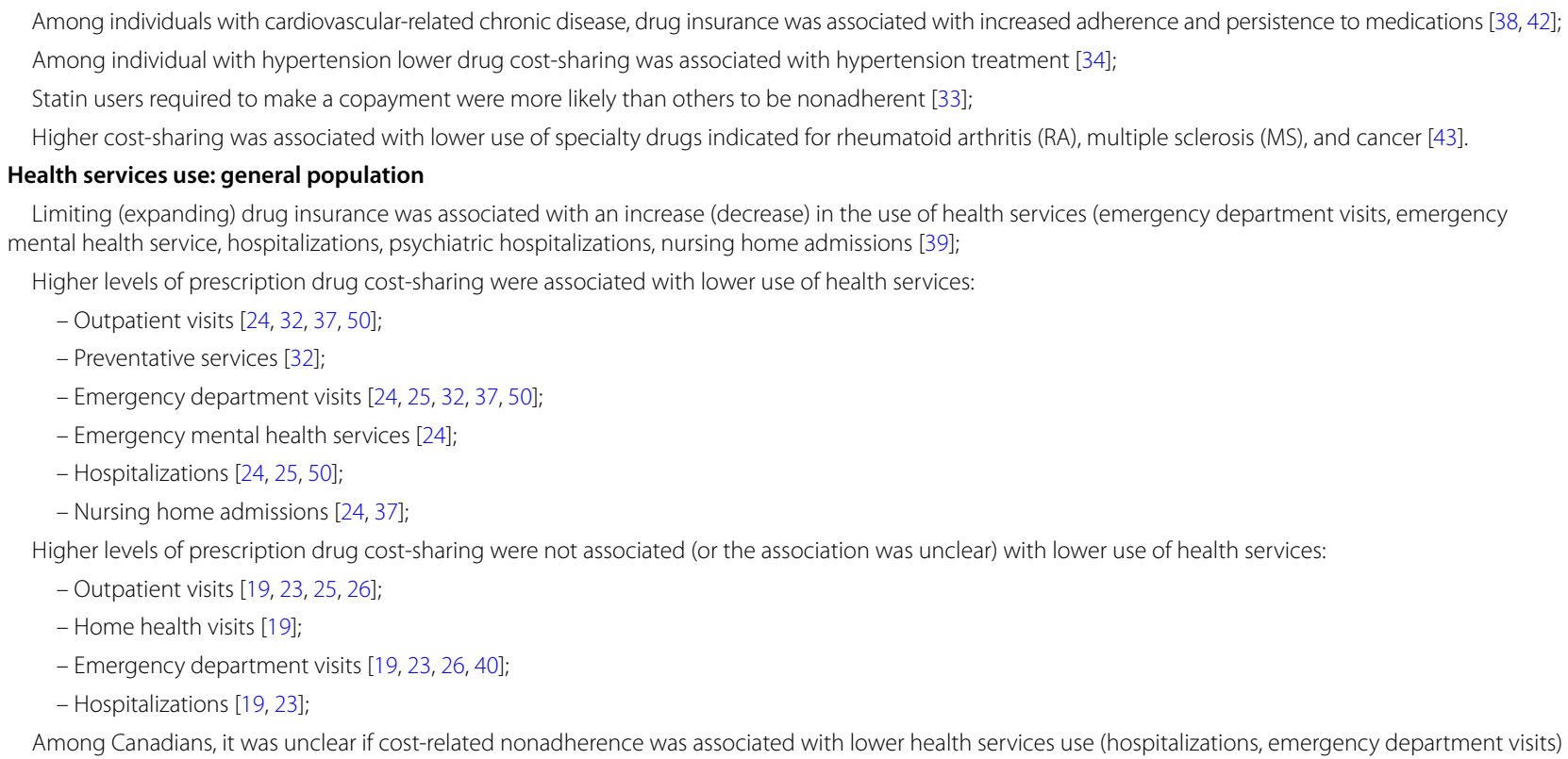

Among individuals with heart failure or diabetes mellitus, higher levels of prescription drug cost-sharing were generally not associated with lower use of health services (outpatient visits, emergency department visits, hospitalizations, or laboratory/diagnostic tests) [45];

Among individuals affected by US federal and state generic drug policies, government insurance plans with high-cost sharing on generic drugs were associated with less use of health services among children [51].

\section{Health: general population}

Evidence on the association between prescription drug cost-sharing and health suggested that higher drug cost-sharing generally lowered health status [24, 32, 50];

Evidence on the association between prescription drug cost-sharing and health was limited and/or unclear [16, 19, 23, 25, 26, 29, 30, 46];

Evidence on the association between prescription drug insurance and health was limited, but generally indicated a positive association [39].

\section{Health: older adults, seniors}

Among seniors, evidence on the association between prescription drug cost-sharing and health was limited and/or unclear [20,35].

\section{Health: socioeconomic status, chronically ill}

Some evidence that higher cost-sharing was associated with poorer health among the poor and chronically ill $[17,23,29,30]$.

was supported by all other reviews except one [25]. However, when comparing price responsiveness between the poor and non-poor, four reviews provided mixed or no evidence that individuals with lower income were more price sensitive than those with higher income [23-25, 27]. Although one review concluded that higher copayments led to a greater reduction in drug use in vulnerable populations (low socioeconomic status measured by income, education, or social status) than the non-vulnerable population) [37].
With respect to the chronically ill, reviews generally concluded that higher copayments or the absence of drug insurance were associated with increased medication nonadherence for a range of illnesses and drug classes [17, 23, 25, 27, 33, 34, 38, 42-49]. However, the magnitude of effects was often unclear and difficult to synthesize given the diverse outcome measures employed in each review. A recent meta-analysis focusing on individuals with chronic cardiovascular diseases found that access to insurance or other programs 
Table 3 Results - association between prescription drug insurance/cost-sharing and drug use, general population

\begin{tabular}{|c|c|}
\hline Authors, year & Results - drug use, general population \\
\hline $\begin{array}{l}\text { Harten, Ballantyne, } 2004 \text { [16]; } \\
\text { - Canadians }\end{array}$ & $\begin{array}{l}\text { Found either no change in utilization or a decrease in essential and nonessential medications following } \\
\text { introduction of or increases in drug cost-sharing. } \\
\text { Magnitude: unclear. }\end{array}$ \\
\hline Gibson, Ozminkowsky, Goetzel, 2005 [19]; & $\begin{array}{l}\text { - Demand for prescription drugs } \\
\text { Higher levels of drug cost-sharing resulted in reductions in prescription drug use. } \\
\text { Magnitude: most estimates of own-price elasticity suggested that a 10\% increase in price decreased use by } \\
1 \text { to } 4 \% \text {. } \\
\text { - Medication adherence: } \\
\text { Patients facing cost-sharing were less likely to adhere to prescribed medications. } \\
\text { Magnitude: unclear. } \\
\text { - Non-preferred vs. preferred brand-name drugs: } \\
\text { All studies reviewed showed that increasing drug cost-sharing for non-preferred brand-name drugs } \\
\text { decreased use of non-preferred brand-name drugs and increased use of preferred brand-name drugs. } \\
\text { Magnitude: unclear. } \\
\text { - Generic substitution: } \\
\text { Little evidence of generic substitution in plans introducing or increasing a generic vs brand cost-sharing } \\
\text { differential. } \\
\text { Magnitude: unclear. } \\
\text { - Substitution of over-the-counter drugs for prescription drugs: } \\
\text { Limited and inconclusive findings. } \\
\text { Magnitude: unclear. } \\
\text { - Essential medications: } \\
\text { Higher levels of prescription drug cost-sharing were associated with a reduction in the consumption of } \\
\text { essential medications. } \\
\text { Magnitude: unclear. }\end{array}$ \\
\hline
\end{tabular}

Briesacher, Gurwitz, Soumerai, 2007 [21]; Not having prescription drug coverage was a significant and robust risk factor for cost-related nonadherence in all reviewed studies.

Magnitude: unclear; duration of coverage and type of coverage affected the magnitude of associations.

Gemmil, Costa-Font, McGuire, 2007 [23]; Higher cost-sharing was negatively associated with the demand for prescription drugs. Magnitude: the demand for prescription drugs was relatively inelastic. The estimated corrected own-price elasticity was - 0.21 (mean standard error 0.026); a 10\% increase in cost-sharing was associated with a 2\% decrease in pharmaceutical spending.

Goldman, Joyce, Zheng, 2007 [23];

- Demand for prescription drugs

Higher cost-sharing was negatively associated with the demand for prescription drugs.

Magnitude: the demand for prescription drugs was relatively inelastic. Own-price elasticities ranged from -0.2 to -0.6 ; cost-sharing increases of $10 \%$ (through either higher copayments or coinsurance) were associated with a 2 to $6 \%$ decline in prescription drug use. The magnitude of association depended on class of drug and condition of patients.

- Essential and nonessential drug use

Mixed effects of the impact of copayments on essential drug use.

Magnitude: unclear.

Gemmil, Thomson, Mossialos, 2008 [24]; - Demand for prescription drugs

Individuals who faced prescription drug charges were less likely to use prescription drugs while those with insurance coverage were more likely to use them.

Magnitude: overall, the demand for prescription drugs was almost always inelastic. Studies that used aggregate data generally found that a 10\% increase in price resulted in a 0.6 to $8 \%$ decrease in use while studies that used individual- or household-level data generally found that a $10 \%$ increase in price resulted in a 0.2 to $6 \%$ decrease in use.

- Volume of drug use:

Most studies included found a negative relationship between prescription cost-sharing and levels of prescription drug use while insurance coverage had a positive effect on the volume of drug used. Magnitude: unclear.

- Brand-name vs generic drugs:

The demand for brand-name drugs was more price-elastic than that of generic drugs.

Magnitude: The demand for brand-name and the demand for generic drugs were both relatively inelastic.

- Essential and nonessential drug use:

Most studies found that prescription drug charges lowered the use of essential and nonessential drugs, although reductions in the use of nonessential drugs were usually slightly larger. Magnitude: unclear.

Remler, Greene, 2009 [25];

There was an inverse association between pharmaceutical cost-sharing and pharmaceutical spending/use. There was mixed evidence that pharmaceutical cost-sharing affected essential drugs differently. Magnitude: on average, a 10\% increase in pharmaceutical cost-sharing (measured as equivalent coinsurance) resulted in decreases of 2 to $6 \%$ in pharmaceutical spending/use. 
Table 3 (continued)

\begin{tabular}{|c|c|}
\hline Authors, year & Results - drug use, general population \\
\hline Green, Maclure, et al., 2010 [26]; & $\begin{array}{l}\text { Restriction to reimbursement decreased drug use, either immediately after policy implemented or long- } \\
\text { term. Impact varied by drug class and whether restrictions were implemented or relaxed. } \\
\text { Magnitude: unclear. }\end{array}$ \\
\hline Holst, 2010 [27] & $\begin{array}{l}\text { Consistent findings that increasing prescription cost-sharing reduced drug use and patient compliance to } \\
\text { drug therapies. Effect varied depending on class of substance. } \\
\text { Magnitude: unclear. }\end{array}$ \\
\hline Swartz, 2010 [29]; & $\begin{array}{l}\text { Increased cost-sharing for prescription drugs was associated with declines in use and spending on drugs. } \\
\text { The evidence was unclear whether people responded to increased cost-sharing by switching to less } \\
\text { expensive, close drug substitutes. With increased cost-sharing, both essential and nonessential drug use was } \\
\text { decreased but the decrease was larger for nonessential drugs. } \\
\text { Magnitude: increased cost-sharing of about 10\% was associated with a decline of between } 1 \text { and } 6 \% \text { in } \\
\text { spending on prescription drugs. }\end{array}$ \\
\hline Baicker, Goldman, 2011 [30]; & $\begin{array}{l}\text { Higher cost-sharing was negatively associated with the demand for prescription drugs. } \\
\text { Magnitude: The evidence suggested a price elasticity for drug expenditures of }-0.2 \text { to }-0.6 \text {. The range } \\
\text { reflected differences in responsiveness by drug class and its importance. }\end{array}$ \\
\hline Eaddy, Cook, et al., 2012 [32]; & $\begin{array}{l}\text { Most studies found a statistically significant relationship between increased patient drug cost-sharing and } \\
\text { decreased medication adherence. The effect depended on the population and intervention. } \\
\text { Magnitude: overall, a } \$ 10 \text { increase was associated with a 3.8\% decrease in adherence. }\end{array}$ \\
\hline $\begin{array}{l}\text { Sinnott, Buckley, et al., } 2013 \text { [36]; } \\
\text { - Publicly insured populations }\end{array}$ & $\begin{array}{l}\text { There was a positive association between copayments and nonadherence. } \\
\text { Magnitude: summary odds ratio for nonadherence was } 1.11(95 \% \mathrm{Cl} 1.09,1.14) \text {; publicly insured patients who } \\
\text { were required to pay copays for their prescription medicines had } 11 \% \text { higher odds of reporting nonadher- } \\
\text { ence relative to those who faced no copayments. }\end{array}$ \\
\hline Kiil, Houlberg, 2014 [37]; & $\begin{array}{l}\text { Overall, pharmaceutical copayments had negative effects on the use of prescription medicine. The extent to } \\
\text { which copayment affected the use of prescription medicine depended on the type of medicine as well as } \\
\text { the patient population. } \\
\text { Magnitude: unclear. }\end{array}$ \\
\hline Kesselheim, Huybrechts et al., 2015 [39]; & $\begin{array}{l}\text { - Prescription drug insurance coverage } \\
\text { Three studies examined the impact of drug insurance on patients' use of drugs and adherence by compar- } \\
\text { ing cohorts of patients with and without coverage. Two of three studies found that those with insurance } \\
\text { used more drugs. } \\
\text { Magnitude: unclear. } \\
\text { - Extending drug insurance } \\
\text { Magnitude: one study examined the effects of extending drug coverage to patients on their drug use and } \\
\text { found that the number of prescription fills increased non-significantly by } 2 \text { per patient-year. } \\
\text { - Drug insurance restriction } \\
\text { Six studies evaluated the effects of drug insurance restrictions on drug utilization and adherence. All studies } \\
\text { found that drug insurance restrictions led to lower drug utilization and/or adherence. } \\
\text { Magnitude: unclear. }\end{array}$ \\
\hline Luiza, Chavez et al., 2015 [40]; & $\begin{array}{l}\text { Raising direct patient payments for medicines was found to reduce the use of both important and unimpor- } \\
\text { tant drugs. The impact was sometimes uncertain and varied from small to moderate relative reductions. } \\
\text { Magnitude: unclear. }\end{array}$ \\
\hline Aziz, Hatah, et al., 2016 [41]; & $\begin{array}{l}\text { Lower cost-sharing, higher prescription caps, subsidies, and insurance were associated with higher medica- } \\
\text { tion adherence. } \\
\text { Magnitude: unclear. }\end{array}$ \\
\hline $\begin{array}{l}\text { Gupta, McColl et al., } 2018[46] ; \\
\text { - Canadians }\end{array}$ & $\begin{array}{l}\text { Having prescription drug insurance was significantly associated with having access to prescription medica- } \\
\text { tion without financial barriers. High drug costs (> 5\% of annual household income or }>\$ 20 \text { a month out-of- } \\
\text { pocket) was a major determinant of cost-related nonadherence. } \\
\text { Magnitude: unclear. }\end{array}$ \\
\hline $\begin{array}{l}\text { Mishuk, Fasina, Qian, } 2019[51] \text {; } \\
\text { - Individuals affected by US federal and } \\
\text { state generic drug policies }\end{array}$ & $\begin{array}{l}\text { Seven studies found that policies lowering prescription cost-sharing were associated with increased } \\
\text { patient's medication use and adherence, but the impact varied by therapeutic classes. } \\
\text { Magnitude: unclear }\end{array}$ \\
\hline
\end{tabular}

that assisted with medication costs resulted in a $37 \%$ decrease in the risk of medication nonadherence [48]. Another recent review examined the association between cost-sharing on specialty drugs for rheumatoid arthritis, multiple sclerosis, and cancer, and the use of specialty drugs and nondrug medical services, and health outcomes [43]. Although no research was found that pertained to the use of nondrug medical services and health outcomes, the review found that higher cost-sharing was associated with higher prescription abandonment and discontinuation/persistence, and lower initiation and adherence. Findings 
Table 4 Results - association between prescription drug insurance and cost-sharing and drug use, for/between specific populations

\begin{tabular}{l} 
Authors, year / population $^{\text {a }}$ \\
\hline Older adults, seniors \\
Adams, Soumerai, Ross-Degnan, 2001 [15]; \\
- US Medicare population (65+ years)
\end{tabular}

Rice, Matsuoka, 2004 [18];

- Seniors

Maio, Pizzi, Roumm, 2005 [20];

- Seniors

Briesacher, Gurwitz, Soumerai, 2007 [21];

- General population

Gemmil, Thomson, Mossialos, 2008 [24]

- General population

Holst, 2010 [27];

- General population

Polinski, Kilabuk, et al., 2010 [28];

- US Medicare population (65+ years)

Swartz, 2010 [29];

- General population

Baicker, Goldman, 2011 [30];

- General population
Results - drug use, for/between specific populations

In the US Medicare population, drug coverage was associated with greater use of all drugs and clinically essential medications.

Magnitude, seniors: reductions in drug use ranged between 21 and 46\% depending on the drug class and condition of patients.

Magnitude, seniors vs. non-seniors: unclear.

Among seniors, cost-sharing (not necessarily for drugs) was found to reduce the appropriate use of prescription drugs (medications that were thought to improve health status).

Magnitude, seniors: unclear.

Magnitude, seniors vs. non-seniors: unclear.

There was mixed evidence that prescription cost-sharing mechanisms (copayment, coinsurance, and deductible) reduced seniors' drug use. There was some evidence that for low-income populations, even small copayments, may have led them to reduce their use of effective medications.

Magnitude, seniors: unclear.

Magnitude, seniors vs. non-seniors: unclear.

There was strong evidence that among medicare beneficiaries, drug coverage decreased the risk of cost-related medication nonadherence; strong evidence that among medicare beneficiaries and adults 50+, higher cost-sharing increased the risk of cost-related medication nonadherence.

Magnitude, older adults, seniors: unclear.

Magnitude, older adults, seniors: vs. non-older adults, non-seniors: unclear.

Older people were not found to be more sensitive to price than the general population.

Magnitude, older adults: a 10\% increase in price led to changes in use for older people ranging from a $5.6 \%$ reduction to a $0.9 \%$ increase based on non-aggregate data, and one study using aggregate data found a reduction of $5.1 \%$.

Magnitude, older adults vs. non-older adults: among the general population, price elasticity estimates suggested that a $10 \%$ increase in price led to a 0.2 to $4.6 \%$ decrease in use based on non-aggregate data and a 0.9 to $8.0 \%$ decrease in use based on aggregate data.

Older people responded especially sensitively to cost-sharing.

Magnitude, older adults: unclear.

Magnitude, older adults vs. non-older adults: unclear.

The inception of Medicare Part D was associated with a consistent overall increase in drug use. There was little variation in effect estimates between studies evaluating the effect of Part D implementation. Across all studies, entry of Part D beneficiaries into the coverage gap was associated with reduced drug use.

Magnitude, seniors: the inception of Part D was associated with a 6 to $13 \%$ increase in drug use. Changes in use varied according to drug, disease, and population studied. There was little indication that Part D selectively led to greater use of essential, underused drugs than of overused medications. Across all studies, entry of Part D beneficiaries into the coverage gap was associated with 9 to $16 \%$ less drug use. Patients who entered the coverage gap were 5 to $11 \%$ more likely to report discontinuing, switching, or failing to initiate a medication than were patients who did not enter the coverage gap. Use of generic drugs increased $20 \%$ during the coverage gap.

Magnitude, seniors vs. non-seniors: unclear.

Cost-sharing reduced use of essential drugs in people with chronic conditions and the elderly. Studies that looked at the Medicare doughnut hole found that elderly reduced drug use when they had to pay full price.

Magnitude, elderly: one study in the elderly found cost-sharing reduced essential drugs by $9 \%$ for essential drugs and 15\% for nonessential drugs. Magnitude, elderly vs non-elderly: unclear.

One study that examined Medicare Part D found that providing insurance to the elderly led to increased prescription drug use.

Magnitude, seniors: providing insurance to the elderly led to a 13\% increase in prescription drug use. Further interpretation not provided Magnitude, seniors vs. non-seniors: unclear. 
Table 4 (continued)

Authors, year / population ${ }^{\mathrm{a}}$

Polinski, Donohue, et al., 2011 [31];

- US Medicare population (65+ years)

Pimentel, Lapane, Briesacher, 2013 [35];

- US Medicare population (65+ years) in long-term care

Park, Martin, 2017 [7];

- US Medicare population (65+ years)

Ofori-Asenso, Jakhu et al., 2018 [47];

$-65+$ years statins users

Mishuk, Fasina, Qian, 2019 [51]

- Individuals affected by US federal and state generic drug policies

\section{Results - drug use, for/between specific populations}

In the period after Medicare Part D implementation there was an increase in the use of essential medicines especially in beneficiaries who had been previously uninsured, and of nonessential medicines. During the transition period, dually eligible beneficiaries' drug use remained largely unchanged. In the coverage gap, when cost-sharing increased, the use of essential and overused medications declined.

Magnitude, seniors: unclear

Magnitude, seniors vs. non-seniors: unclear.

Findings of prescription drug utilization were mixed. Prescription drug benefit was associated with decreased use of drugs that carry safety concerns, but overall drug utilization may have been unaffected. A shift in drug utilization within drug classes was seen (i.e., from non-covered to covered drugs and utilization of new drugs to treat side effects).

Magnitude, seniors: unclear.

Magnitude, seniors vs. non-seniors: unclear.

Studies consistently found that Medicare Part D increased drug utilization across numerous outcomes, including medication persistence, number of days with possession of at least 1 drug within a class, annual prescription fills per person, drug access, and cost-related behaviour changes such as medication cessation, applying to pharmaceutical assistance programs, and receiving free prescription samples. Similarly, Medicare Part D coverage gaps negatively impacted drug utilization. The coverage gap prompted some substitution of generic for brand-name drugs. Magnitude, seniors: the strongest effect sizes were for medication use and increases were highest among beneficiaries receiving low-income subsidies.

Magnitude, seniors vs. non-seniors: unclear.

Higher copayment/cost (not necessarily drug cost-sharing) increased the likelihood of nonadherence and of discontinuation.

Magnitude, seniors: the association between higher copayment and nonadherence and discontinuation was positive (OR 1.4, 95\% Cl 1.3, 1.5; OR 1.6, 95\% Cl 1.5, 1.7). Further interpretation not provided.

Magnitude, seniors vs. non-seniors: unclear.

Existing evidence evaluating Medicare Part D suggested decreased prescription spending for beneficiaries and increased use of generics. Policies lowering costsharing were associated with increased patient's medication use and adherence, but the impact varied by therapeutic classes while government insurance plans with higher cost-sharing were associated with reduced generic utilization. Evidence suggested that lower cost-sharing increased generic drug use which further enhanced medication adherence.

Magnitude, seniors: unclear.

Magnitude, seniors vs. non-seniors: unclear.

\section{Socioeconomic status, chronically ill}

Lexchin, Grootendorst, 2004 [17];

- The poor and chronically ill

Cost-sharing through the use of copayments or deductibles decreased the use of prescription drugs by the poor and the chronically ill.

Magnitude, poor/chronically ill: drug price elasticities among vulnerable groups those with low income and/or chronic illnesses - generally ranged from -0.34 to -0.50 . Some evidence that cost-sharing led to patients foregoing essential medications.

Magnitude, poor/chronically ill: vs. non-poor/chronically ill: unclear.

Goldman, Joyce, Zheng, 2007 [23];

- General population
- Low-income

Although studies suggested that low-income beneficiaries reduced drug use with higher copayments, there was little evidence that individuals of lower-income were more sensitive to increased cost-sharing than the general population. Magnitude, low-income: same as the general population.

Magnitude, low-income vs. non-low-income: same as the general population.

- Chronically ill

The evidence suggested that even chronically ill patients were responsive to costsharing.

Magnitude, chronically ill: unclear.

Magnitude, chronically ill vs. non-chronically ill: unclear. 
Table 4 (continued)

\section{Authors, year / population ${ }^{\mathrm{a}}$}

Gemmil, Thomson, Mossialos, 2008 [24];

- General population

Remler, Greene, 2009 [25];

- General population

Holst, 2010 [27];

- General population

Swartz, 2010 [29];

- General population

Lemstra, Blackburn et al., 2012 [33]

- Statin users

Maimaris, Paty, et al., 2013 [34];

- Individuals with hypertension

Kiil, Houlberg, 2014 [37];

- General population

\section{Results - drug use, for/between specific populations}

Poorer people were not found to be more sensitive to price than the general population.

Magnitude, poor: among the poor, a 10\% increase in price led to reductions in use ranged from 0.3 to $2.0 \%$ based on non-aggregate data and 0.5 to $4.0 \%$ based on aggregate data.

Magnitude, poor vs. non-poor: among the general population, a 10\% increase in price led to a 0.2 to $4.6 \%$ decrease in use based on non-aggregate data and a 0.9 to $8.0 \%$ decrease in use based on aggregate data.

- Low-income

Evidence has not consistently shown a relationship between income and costsharing effects; the findings were mixed and not conclusive, and the work was limited by the relatively homogenous populations and proxy measures of income. Magnitude, low-income: unclear.

Magnitude, low-income vs. mid-, high-income: unclear.

- Chronically ill

Only a few studies compared the impact of cost-sharing on different health status groups; pharmaceutical cost-sharing among those with chronic disease sometimes reduced the use of valuable drugs; several studies conducted on chronically ill populations (including those with rheumatoid arthritis, heart failure, diabetes, schizophrenia, and lipid disorders) found unambiguous reductions in the use of drugs regarded as important for maintaining the health of the chronically ill. Magnitude, chronically ill: unclear.

Magnitude, chronically ill vs. non-chronically ill: unclear.

- Low-income

Some evidence that lower-income individuals were sensitive to increased costsharing.

Magnitude, subgroup: unclear.

Magnitude, low-income vs. mid-, high-income: unclear.

- Chronically ill

Cost-induced nonadherence to medical recommendations was observed more often among people who needed treatment than among healthy citizens. Magnitude, chronically ill: unclear.

Magnitude, chronically ill vs. non-chronically ill: unclear.

One study that examined changes in prescription drug copayments imposed on privately insured people indicated that for each medication class examined, individuals living in high-income areas were consistently more likely to continue taking their medications than people in low-income areas after copayments increased.

Magnitude, poor: unclear.

Magnitude, poor vs non-poor: unclear.

Statin users required to make a copayment were more likely than others to be nonadherent.

Magnitude, statin users: among 6 studies with a total sample size of 884,643 patients required to make a copayment when their statin medications were dispensed were $28 \%$ more likely than others to be nonadherent (rate ratio $1.3 ; 95 \% \mathrm{Cl}$ 1.1, 1.5).

Magnitude, statin users vs. non-statin users: unclear.

Health insurance and lower cost-sharing were associated with hypertension treatment (defined as the use of at least one antihypertensive medication in an individual with known hypertension) and antihypertensive medication adherence. Magnitude, individuals with hypertension: unclear. Magnitude, individuals with hypertension vs. individuals without hypertension: unclear.

The majority of studies found that copayments led to a larger reduction in the use of prescription medicine for vulnerable population groups than for the non-vulnerable general population.

Magnitude, vulnerable population: unclear.

Magnitude, vulnerable population vs. non-vulnerable general population: unclear. 
Table 4 (continued)

\section{Authors, year / population ${ }^{\mathrm{a}}$}

Mann, Barnieh, et al., 2014 [38];

- Individuals with cardiovascular-related chronic disease

Banerjee, Khandelwal, et al., 2016 [42];

- Individuals with cardiovascular diseases

Doshi, Li et al., 2016 [43];

- Individuals using specialty drugs

Powell, Saloner, Sabik, 2016 [44];

- Medicaid beneficiaries

\section{Results - drug use, for/between specific populations}

The addition of drug insurance for those without previous drug insurance appear to have consistently increased adherence to medications. In general, studies evaluating drug insurance cost-sharing strategies had conflicting results with some studies showing significant differences in some outcomes while other studies demonstrated no discernible difference in outcomes. The use of deductibles (up to $\$ 350$ per year) did not appear to have a significant impact on medication adherence. The impact of a maximum out-of-pocket limits was uncertain. Magnitude, chronically ill: unclear.

Magnitude, chronically ill vs. non-chronically ill: unclear.

Reduced copayments and full prescription coverage were associated with increased adherence and persistence.

Magnitude, individuals with cardiovascular diseases: two retrospective cohort studies investigated the impact of copayments on adherence; 1) among 4105 patients with acute myocardial infarction in Austria, those with waived copayments had higher persistence at 120 days for drug therapy with aspirin, statins, angiotensinconverting enzyme inhibitors (ACEI) or angiotensin-receptor blockers (ARB) than those with copayments (OR 1.4,95\%Cl 1.1,1.7), but $\beta$ blocker (OR 1.1,95\%Cl 0.9, 1.4) or statin use (OR $1.1,95 \% \mathrm{Cl} 0.9,1.3)$ did not significantly differ between these groups; 2) a US study of coronary heart disease patients found that compared with copayments $<$ US $\$ 10$, copayments $\geq$ US $\$ 20$ were associated with lower persistence at 1 year for statins (OR $0.42 ; 95 \% \mathrm{Cl} 0.36$ to 0.49 ). A US-based RCT included 5855 individuals post-myocardial infarction, randomized to full or usual prescription coverage. Full adherence was higher with full prescription coverage for all medication classes (OR 1.4, 1.2, 1.7). Increased adherence to all three medications for the patient subgroup undergoing coronary artery bypass graft was found, post hoc (OR 1.7, 95\% Cl 1.04 to 2.7 ).

Magnitude, individuals with cardiovascular diseases vs. individuals without cardiovascular diseases: unclear.

- Prescription abandonment (prescription submitted and approved by the insurer but not obtained by the patient): all studies $(n=3)$ reported a strong association of higher cost-sharing with abandonment (vs initiation) of specialty drug prescriptions, for all indications examined.

Magnitude, individuals using specialty drugs: unclear.

- Initiation (first time use of specialty drug within a study period): all studies $(n=8)$ examining initiation in patients with rheumatoid arthritis and multiple sclerosis reported a negative association with higher cost-sharing. Initiation of specialty drugs for cancer was largely reported to be insensitive to cost-sharing in the 3 studies examining this outcome.

Magnitude, individuals using specialty drugs: the demand elasticity ranged from -0.03 to -0.33 for patients with rheumatoid arthritis or multiple sclerosis.

- Adherence: evidence on relationship between cost-sharing and adherence was mixed. The majority of studies reported a statistically significant increase in discontinuation associated with increased cost-sharing.

Magnitude, individuals using specialty drugs: unclear.

- Discontinuation/persistence (having a continuous gap of time between prescription fills): 6 of the 7 studies reported a statistically significant increase in discontinuation (or decrease in persistence) associated with increased cost-sharing for at least 1 of the indications examined.

Magnitude, individuals using specialty drugs: the magnitude of the effects appeared small.

Increasing copayments resulted in decreased utilization of drugs and higher rates of non-adherence. However, the magnitude of these associations varied across subgroups.

In patients with high need for prescription drugs, studies found that increased copayments resulted in decreased adherence. This was found in Medicaid patients with schizophrenia and privately insured adults with diabetes and congestive heart failure who were living in lowest median income areas.

Magnitude, chronically ill: unclear. Magnitude, chronically ill vs non-chronically-ill: unclear.

Magnitude, poor: unclear.

Magnitude, poor vs non-poor: unclear. 
Table 4 (continued)

\begin{tabular}{|c|c|}
\hline Authors, year / population ${ }^{a}$ & Results - drug use, for/between specific populations \\
\hline $\begin{array}{l}\text { Gourzoulidis, Kourlaba, et al., } 2017 \text { [45]; } \\
\text { - Individuals with heart failure or diabetes mellitus }\end{array}$ & $\begin{array}{l}7 \text { of } 8 \text { studies evaluating the relationship between drug copayment and medica- } \\
\text { tion adherence in diabetes mellitus population and } 1 \text { of } 3 \text { in heart failure popula- } \\
\text { tion, found a statistically significant inverse association between increases in } \\
\text { copayments and medication adherence. } \\
\text { Magnitude, individuals with heart failure or diabetes mellitus: unclear. } \\
\text { Magnitude, individuals with heart failure or diabetes mellitus vs. individuals without } \\
\text { heart failure or diabetes mellitus: unclear. }\end{array}$ \\
\hline $\begin{array}{l}\text { Gupta, McColl et al., } 2018 \text { [46]; } \\
\text { - Canadians }\end{array}$ & $\begin{array}{l}\text { Three studies including people with cardiovascular conditions found that those } \\
\text { spending } \geq 5 \% \text { costs of medications out of their pocket were more likely to report } \\
\text { cost-related non-adherence than those spending }<5 \% \text {. } \\
\text { Magnitude, chronically ill: unclear. } \\
\text { Magnitude, chronically ill vs. non-chronically ill: unclear. }\end{array}$ \\
\hline $\begin{array}{l}\text { Schneider, Gaedke et al., } 2018 \text { [48]; } \\
\text { - Individuals with chronic cardiovascular diseases }\end{array}$ & $\begin{array}{l}\text { Among individuals with chronic cardiovascular diseases, access to insurance or } \\
\text { other programs that assisted with medication costs was a protective factor for } \\
\text { nonadherence. } \\
\text { Magnitude, chronically ill: insurance or programs that assisted with medication cost } \\
\text { was correlated with a } 24 \% \text { decrease in the risk of nonadherence (OR } 0.76 ; 95 \% \mathrm{Cl} \\
0.60,0.95) \text {. } \\
\text { Magnitude, chronically ill vs. non-chronically ill: unclear. }\end{array}$ \\
\hline $\begin{array}{l}\text { Cheen, Tan et al., } 2019 \text { [49]; } \\
\text { - Individuals with any of six common chronic diseases. }\end{array}$ & $\begin{array}{l}\text { On the whole, among individuals with chronic diseases (asthma, chronic obstruc- } \\
\text { tive pulmonary disease, depression, diabetes mellitus, hyperlipidaemia, hyperten- } \\
\text { sion and osteoporosis), higher copayments were associated with primary medica- } \\
\text { tion nonadherence. } \\
\text { Magnitude, chronically ill: a high copayment amount had the strongest associa- } \\
\text { tion with primary medication nonadherence, with ORs ranging from } 1.01 \text { to } 33 \\
\text { (compared to lower copayments); } \\
\text { Magnitude, chronically ill vs. non-chronically ill: unclear. }\end{array}$ \\
\hline
\end{tabular}

a Population examined by each included review

varied by diseases but generally indicated stronger effects for noninitiation or abandonment of a prescription at the pharmacy and somewhat smaller effects for refill behaviour once patients initiated therapy [43]. Lastly, we are unable to comment on how the impact of cost-sharing or drug insurance on drug use compared to drug use by the healthy population as such comparisons were not drawn in the literature.

The elderly was the most studied group apart from the chronically ill, with 14 reviews focusing on this particular population. Of the 14 reviews, 11 concluded that seniors were sensitive to price changes $[7,15,18,21$, $27-31,47,51]$; drug use decreased with increasing costsharing or the lack of drug insurance, with the others finding mixed or no evidence for price responsiveness among older adults [20, 24, 35]. Again, the magnitude of effect was difficult to evaluate, and we are unable to comment on age differences (elderly vs non-elderly) in price responsiveness.

Only two reviews mentioned potential sex/gender differences in responsiveness to changes in cost-sharing or insurance. One review reported that one study had found that a drug policy change had not reduced the use of essential cardiac medications among Québec elderly who experienced acute myocardial infarction and that this finding did not vary by sex [23]. Another review reported that one study had found that lowincome single elderly women were much less price responsive to drug fees than low-income single elderly men in British Columbia [17].

\section{Associations of prescription drug insurance and cost-sharing with health services use}

On the whole, most reviews concluded that increasing prescription drug cost-sharing or limiting drug insurance were associated with higher healthcare services utilization, such as emergency room visits, hospitalizations, and outpatient visits in the general population, although the magnitudes of associations were unclear (Tables 2 and 5) [24, 25, 30, 32, 37, 39, 50]. Two older reviews (published in 2005 and 2007) found no evidence of associations between prescription drug cost-sharing and changes in the use of healthcare services such as outpatient visits or hospitalizations $[19,23]$ while three relatively more recent reviews from 2010, 2015, and 2018 concluded the evidence was mixed or uncertain $[26,40,46]$.

\section{Differences between subgroups: SES, health status, age, and sex/gender}

When assessing results by subgroups, the findings were generally the same as those reported in the general population (Tables 2 and 6). Three reviews that focused on 
Table 5 Results - association between prescription drug insurance/cost-sharing and healthcare services utilization, general population

Authors/year/population

Gibson, Ozminkowsky, Goetzel, 2005 [19];

Goldman, Joyce, Zheng, 2007 [23];

Gemmil, Thomson, Mossialos, 2008 [24];

Remler, Greene, 2009 [25];

Green, Maclure, et al., 2010 [26];

Eaddy, Cook, et al., 2012 [32];

Kiil, Houlberg, 2014 [37];

Kesselheim, Huybrechts et al., 2015 [39];

Luiza, Chavez et al., 2015 [40];

Gupta, McColl et al., 2018 [46];

- Canadians

Kolasa, Kowalcyzk, 2019 [50];

\section{Results - healthcare services utilization, general population}

In most studies, higher levels of prescription drug cost-sharing were not associated with changes in the utilization of low-intensity outpatient medical services, such as physician office visits, outpatient visits, and home health visits. However, these studies assessed small changes in prescription drug cost sharing. Two studies reported an increase in high-intensity health services (such as inpatient visits, emergency department visits, readmissions among older patients hospitalized with complications after acute myocardial infarction) as cost-sharing rose in some diagnostic groups (congestive heart failure or coronary artery disease) while not in others (diabetes mellitus). Four studies reported no association between higher levels of cost-sharing and high-intensity services.

Magnitude: $\mathrm{n} / \mathrm{a}$

Increased drug copayments were not associated with more outpatient visits, hospitalizations, or emergency department visits among a broader population (not restricted to the elderly or those with chronic conditions).

Magnitude: $\mathrm{n} / \mathrm{a}$

There was generally a positive relationship between prescription drug cost-sharing and outpatient, inpatient, and emergency care. Studies also found that prescription limits increased the frequency of partial hospitalization and nursing home admissions and the use of emergency mental health service. Two studies that found no effect were based on chronically ill patients.

Magnitude: unclear.

Some evidence suggested that pharmaceutical cost-sharing increased emergency department use and hospitalizations; limited evidence about resulting increases in outpatient care.

Magnitude: unclear.

The effects of pharmaceutical reimbursement on health care access were uncertain. Some studies reported an immediate increase in utilization while another found no significant difference in office visits, hospitalization, or length of stay. Very few studies looked at the long-term impact on utilization. One study reported an increase in outpatient services but no change in inpatient and long-term services.

Magnitude: unclear.

Most studies indicated that increased patient drug cost-sharing adversely affected health services utilization (emergency department visits, outpatient visits, preventative services, hospitalizations and nursing-home admissions). Fewer studies indicated that an increase in cost-sharing did not affect medical utilization or number of medical visits.

Magnitude: unclear.

Overall, pharmaceutical copayments had positive effects on the substitution to other types of health care services (such as hospitalization, accident emergency departments, long-term care, general practise consultation);

Magnitude: unclear

Multiple studies found that limiting drug insurance was associated with an increase in the use of health services including emergency department use, hospitalizations, nursing home admissions, psychiatric hospitalizations, outpatient mental health visits, and emergency mental health services; other studies found that the expansion of drug insurance led to reductions in hospitalizations.

Magnitude: one study reported the effect of reaching the coverage limit in Medicare Part D on emergency department use and hospitalizations (RR 1.6; 95\% Cl 1.4, 1.8; RR 1.9,95\%Cl 1.6, 2.1). Another study reported positive associations between reaching the Part D coverage gap and worse outcomes among patients in psychiatric institutions with schizophrenia and bipolar disorder, including hospitalizations (schizophrenia: HR 1.3; 99.5\% CI 1.1, 1.7; bipolar disorder: HR 1.3; 99.5\% Cl 1.0, 1.6).

The effects of pharmaceutical cost-sharing on emergency department use, hospitalization or use of outpatient care were uncertain. Magnitude: unclear.

Evidence regarding the impact of cost-related nonadherence on individual health outcomes such as disease exacerbation, poor self-reported health, increase in symptoms leading to increasing hospitalizations, emergency department visits, or mortality was limited and mixed. Two studies found that relative to those with no drug insurance, the insured made more use of physician services. Magnitude: unclear.

All 11 included studies found positive associations between increases in out-of-pocket expenses for drugs and the use of health care services ( 9 of 11 found associations that were statistically significant). Health care services included physician visits, hospitalization, and emergency room visits.

Magnitude: unclear. 
Table 6 Results - association between prescription drug insurance/cost-sharing and healthcare services utilization, for/between specific populations

Authors/year/population $^{\text {a }}$

\section{Older adults, seniors}

Adams, Soumerai, Ross-Degnan, 2001 [15];

- US Medicare population (65+ years)

Rice, Matsuoka, 2004 [18];

- Seniors

Maio, Pizzi, Roumm, 2005 [20];

- Seniors

Swartz, 2010 [29];

- General population

\section{Socioeconomic status, chronically ill}

Lexchin, Grootendorst, 2004 [17];

- The poor and chronically ill

Goldman, Joyce, Zheng, 2007 [23];

- General population

Remler, Greene, 2009 [25];

- General population

Holst, 2010 [27];

- General population

Swartz, 2010 [29];

- General population
Results - healthcare services utilization, for/between specific populations

The association between prescription drug insurance/cost-sharing and healthcare services utilization were not explicitly discussed. In the New Hampshire drug cap studies, an increase in nursing home admissions for chronically ill elderly persons was affected by the cap. Hospitalizations during the period of the cap also increased but the difference was not statistically significant. For patients with schizophrenia, use of emergency mental health services and partial hospitalization during the time of the cap increased, and then decreased to near pre-cap levels after the cap was repealed; Magnitude, elderly: elderly Medicaid enrolees in New Hampshire were almost twice as likely to be admitted to nursing homes during the period of the cap as those in New Jersey (RR 1.8; $95 \% \mathrm{Cl} 1.2$, 2.6). In addition, there was a slight trend toward higher rates of hospitalization in the New Hampshire cohort during the period of the cap, but this difference was not statistically significant (RR $1.2 ; 95 \% \mathrm{Cl} 0.8,1.6)$. For patients with schizophrenia, use of emergency mental health services and partial hospitalization during the time of the cap increased by $57 \%$.

Magnitude, elderly vs. non-elderly: unclear.

Results were contradictory and not conclusive for hospitalization and long-term care admission rates in response to cost-sharing or prescription drug payment limits. However, having some form of supplemental insurance was associated with more appropriate health care use, particularly when such supplemental insurance provided coverage for prescription medication. Magnitude, elderly: unclear. Magnitude, elderly vs. non-elderly: unclear.

For seniors, prescription drug cost-sharing and the use of caps may have led to greater risk of hospitalization or admittance to nursing home facilities.

Magnitude, elderly: unclear.

Magnitude, elderly vs. non-elderly: unclear.

Increased cost-sharing for prescription drugs appeared to cause increased expenditures on emergency department services and inpatient hospitalizations by elderly and welfare beneficiaries. Magnitude, elderly: unclear.

Magnitude elderly vs non-elderly: unclear.

Some evidence that prescription drug cost-sharing led to increases in use of emergency services (acute care hospitalization, emergency room admission, long-term care admission), and nursing home admissions.

Magnitude, poor/chronically ill: unclear.

Magnitude, poor/chronically ill vs. non-poor/chronically ill: unclear.

The findings from studies focusing solely on chronically ill patients were unambiguous: for patients with congestive heart failure, lipid disorders, diabetes, and schizophrenia, greater use of inpatient and emergency medical services was associated with higher cost-sharing for prescription drugs. For certain conditions, the evidence clearly indicated that more cost-sharing was associated with increased use of other medical services, such as hospitalizations and emergency department visits. Magnitude, chronically ill: unclear

Magnitude, chronically ill vs. non-chronically ill: unclear

Some studies examined a selective reduction in cost-sharing for selected important chronic medications and found significant increases in their use that might be associated with significant reductions in emergency room and hospital usage. Some evidence suggests that pharmaceutical cost-sharing increased emergency department use and hospitalizations. There was less evidence about increases in outpatient care. Magnitude, chronically ill: unclear.

Magnitude, chronically ill vs. non-chronically ill: unclear.

With certain chronic conditions, an increase in drug copayments led to increased use of other medical services such as consulting practitioners and hospital admissions. Magnitude, chronically ill: unclear. Magnitude, chronically ill vs. non-chronically ill: unclear.

One study argued that the evidence was unambiguous for people with chronic illnesses that higher cost-sharing led to greater use of hospital inpatient and emergency department services. Low-income people in poor health were more likely to suffer adverse outcomes, such as increased rates of emergency department use, hospitalizations, admission to nursing homes when increased cost-sharing caused them to reduce their use of health care, particularly prescription drugs. Magnitude, chronically ill: unclear.

Magnitude, chronically ill vs non-chronically ill: unclear.

Magnitude, low income: unclear.

Magnitude, low income vs high income: unclear. 
Table 6 (continued)

\begin{tabular}{ll}
\hline Authors/year/population $^{\text {a }}$ & Results - healthcare services utilization, for/between specific populations \\
\hline $\begin{array}{l}\text { Powell, Saloner, Sabik, } 2016 ~[44] ; \\
\text { - Medicaid beneficiaries }\end{array}$ & Reduced use of prescription drugs from nonadherence has been linked to adverse consequences. \\
& A study of Medicaid beneficiaries with cancer found that after relatively small copayments were \\
& imposed (\$0.50-\$3.00) in Georgia in 2002, days supply of medication decreased and odds of an ED \\
& visit increased. Outside Medicaid, there is strong evidence from a natural experiment in Québec \\
& where increased copayments for prescription drugs led to a spike in hospitalizations. \\
& Magnitude, chronically ill: unclear. \\
& Magnitude, chronically ill vs non-chronically-ill: unclear. \\
& Studies showed no significant association between copayment change and emergency depart- \\
Gourzoulidis, Kourlaba, et al., 2017 [45]; & ment visits, office visits, hospitalizations or laboratory/diagnostic tests among patients with \\
- Individuals with heart failure or diabetes mellitus & diabetes mellitus. One study found that higher drug copayments were associated with an increase \\
& in emergency department visits among patients with heart failure. \\
& Magnitude, chronically ill: unclear. \\
& Magnitude, chronically ill vs. non-chronically ill: unclear. \\
& A study conducted with elderly and social assistance recipients in Québec found that the introduc- \\
Gupta, McColl et al., 2018 [46]; & tion of cost-sharing was associated with increased rates of emergency department visits. Another \\
- Canadians (elderly, chronically ill, poor) & study found that among elderly patients with rheumatoid arthritis, higher cost-sharing was associ- \\
& ated with more physician visits and among those were admitted to the hospital at least once, there \\
& were more admissions. \\
& Magnitude, poor/chronically ill: unclear. \\
& Magnitude, poor/chronically ill vs. non-poor/chronically ill: unclear.
\end{tabular}

\title{
Children
}

Mishuk, Fasina, Qian, 2019 [51]; - individuals affected by US federal and state generic drug policies

\author{
Government insurance plans with high-cost sharing on generic drugs were associated with less \\ use of health services among children. \\ Magnitude, children: unclear. \\ Magnitude, children vs. adults: unclear.
}

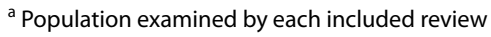

both the poor and chronically ill found that, in most studies reviewed, drug cost-sharing was associated with increased emergency department visits, hospitalizations, and nursing home admissions $[17,29,44]$. The magnitude of these associations was, however, unclear. A more recent review of cost-related nonadherence to prescription medications in Canada provides further support and reported that, among the elderly and individuals on social assistance, the introduction of cost-sharing was associated with increased rates of emergency department and physician visits [46]. It was unclear, however, if any of these associations differed in magnitude when compared to healthier or higher-income populations.

Five reviews specifically discussed the association between prescription drug cost-sharing and healthcare services utilization in the chronically ill $[23,25,27,45$, 46]. Four of these reviews found evidence that prescription drug cost-sharing was associated with increased use of health services including greater hospitalizations, emergency room visits, and nursing home admissions $[23,25,27,46]$. The magnitude of these associations was, however, unclear. One review concluded that there was 'no strong' evidence showing a direct association between drug cost-sharing and healthcare services use among patients with diabetes mellitus, although there was limited evidence that higher drug copayments were associated with an increased risk of hospitalization among patients with heart failure [45]. Nonetheless, it was unclear how chronically ill patients compared to the healthier population in terms of the association between drug-cost sharing and healthcare services use.

Five reviews examined the association between drug cost-sharing or drug insurance and healthcare services utilization in older adults $[15,18,20,29,46]$. Four of these reviews concluded that there was some evidence that higher drug cost-sharing and lack of insurance were associated with greater hospitalizations or nursing home admissions in seniors, although the magnitude was unclear, whereas one older review reported inconclusive findings [18]. It was also unclear how seniors compared to non-seniors with respect to healthcare service utilization when faced with drug cost-sharing. Lastly, one recent review reporting on the association between drug cost-sharing and health services use found that government insurance plans with high-cost sharing on generic drugs were associated with lower use of health services among children. Again, the magnitude of effect was unclear and no comparison was drawn with older individuals [51].

Only one review mentioned potential sex/gender differences in responsiveness to changes in cost-sharing or insurance. One review reported that one study had found that a drug policy change had not reduced the use of medical services among Québec elderly who experienced 
Table 7 Results - association between prescription drug insurance/cost-sharing and health outcomes, general population

\section{Authors/year/population}

Harten, Ballantyne, 2004 [16];

- Canadians

Gibson, Ozminkowsky, Goetzel, 2005 [19]; No

Goldman, Joyce, Zheng, 2007 [23];

Gemmil, Thomson, Mossialos, 2008 [24]

Remler, Greene, 2009 [25];

Green, Maclure, et al., 2010 [26];

Swartz, $2010[29]$

Baicker, Goldman, 2011 [30];

Eaddy, Cook, et al., 2012 [32];

Kiil, Houlberg, 2014 [37];

Kesselheim, Huybrechts et al., 2015 [39];

Gupta, McColl et al., 2018 [46];

- Canadians

Kolasa, Kowalcyzk, 2019 [50];

\section{Results -- health outcomes, general population}

Only one included study examined health outcomes. It found that drug cost-sharing was associated with a decrease in essential drugs, which was associated with an increase in adverse events as measured by hospitalization, nursing home admissions and mortality (in seniors and welfare recipients); Magnitude: unclear.

No studies were identified that measured the effects of prescription drug cost-sharing on direct measures of health status, such as self-reported health status and empirical measures of clinical health status (e.g., laboratory readings). One study found that higher levels of cost-sharing had no effect on mortality rates while another reported an indirect decline in claims-based score of health status because of a copayment increase from $\$ 1$ to $\$ 3$ but not when there there was a copayment increase from $50 \%$ with a $\$ 25$ maximum to $70 \%$ with a $\$ 30$ maximum.

Magnitude: unclear.

The direct evidence on the link between prescription drug cost-sharing and health was limited. Most studies found that when the population was not limited to those with certain chronic illnesses, the outcomes associated with prescription drug cost-sharing were mostly benign. Studies that looked at cost-sharing effects more broadly were ambiguous in their findings.

Magnitude: unclear.

Overall, most studies that directly or indirectly considered the impact of prescription drug charges on health concluded that they lowered or were likely to lower health status because they led patients to forego the use of essential drugs, reduced adherence to treatment, and increased the likelihood of needing more intensive care and of dying. Magnitude of effect: unclear.

There was a lack of direct evidence about pharmaceutical cost-sharing's effect on health. Magnitude: $\mathrm{n} / \mathrm{a}$

Only two of the studies included reported health outcome data, precluding any conclusions about the impact of prior authorization policies on patient outcomes.

Magnitude: $\mathrm{n} / \mathrm{a}$

Very few studies looked at the effect of cost-sharing on health. As such, long-term health effects of reduced use of essential drugs especially people with chronic health conditions is unknown.

Magnitude: $n / a$

Evidence on the ultimate effect of cost-sharing on health outcomes was sparse. Most studies did not examine the effect of coinsurance on health directly. Existing evidence suggested that increased out-of-pocket costs led to lower compliance of drug use, which may indirectly have led to poorer health.

Magnitude: unclear

Most studies indicated that increased patient drug cost-sharing adversely affected health outcomes (outcomes included adverse events, self-reported health status, and symptoms). A few studies found no effect on outcomes and no effect of adherence, supporting the hypothesis that the effect of cost-sharing on outcomes is mediated through adherence;

Magnitude: unclear.

Overall, the effects of copayments on mortality was unclear. The health effects of copayment have only been analyzed empirically in a limited number of studies, of which half did not find any significant effects in the short-term. Some studies observed a drop in the use of essential medicines following an increase in copayment which led to an increase in mortality, while increased drug compliance because of a drop in copayment reduced rate of mortality.

Magnitude: unclear.

- 6 studies evaluated the impact of drug insurance on patients' health by comparing cohorts of patients with and without coverage. 4 of 6 studies found that those with insurance had better treatment adherence and/or health outcomes (self-reported health, mortality, functional disability, hospitalizations);

- 5 studies examined the effects of extending drug coverage to patients on their health outcomes; findings were mixed;

- 5 studies evaluated the effects of drug insurance restrictions on health outcomes; 4 of 5 studies found that drug insurance restrictions led to worse treatment adherence and health outcomes (emergency department use, hospitalizations, health outcomes, rates of death).

Magnitude: unclear.

Few studies reported that cost-sharing for drugs in the form of copayments led patients to forego essential medications and a decline in health care status.

Magnitude: unclear.

Association between drug cost-sharing and health outcomes was reported in 7 studies, of which 5 found statistically significant results of an inverse relationship. 6 studies studied a direct relationship while 1 studied an indirect relationship through adherence. Health outcomes included self-assessed health, major vascular events, cardiovascular-related mortality and all-cause mortality.

Magnitude: unclear 
Table 8 Results - association between prescription drug insurance/cost-sharing and health outcomes, for/between specific population

Authors/year/population ${ }^{\mathrm{a}}$

\section{Older adults, seniors}

Adams, Soumerai, Ross-Degnan, 2001 [15];

- US Medicare population (65+ years)

Rice, Matsuoka, 2004 [18];

- Seniors

Maio, Pizzi, Roumm, 2005 [20];

- Seniors

Pimentel, Lapane, Briesacher, 2013 [35]

- US Medicare population (65+ years) in long-term care

\section{Socioeconomic status, chronically ill}

Lexchin, Grootendorst, 2004 [17];

- The poor and chronically ill

Goldman, Joyce, Zheng, 2007 [23]

- General population

Swartz, 2010 [29];

- General population

Baicker, Goldman, 2011 [30];

- General population

Maimaris, Paty, et al., 2013 [34];

- Individuals with hypertension

Mann, Barnieh, et al., 2014 [38];

- Individuals with cardiovascular-related chronic diseases

Gourzoulidis, Kourlaba, et al., 2017 [45];

- Individuals with heart failure or diabetes mellitus
Results - health outcomes, for/between specific population

Some evidence that cost-sharing and limits on the the number of reimbursable prescriptions led to serious adverse health outcomes for sick and low-income Medicare beneficiaries (nursing home admissions, use of clinic emergency mental health services by schizophrenic patients).

Magnitude, seniors: unclear.

Magnitude, seniors vs. non-seniors: unclear.

Among seniors, cost-sharing (not necessarily drug) resulted in lower health status (either higher mortality or various measures of morbidity), with the following two notable exceptions: 1) when generous provisions were in place to protect vulnerable populations from incurring undue financial risk as a result of cost sharing, 2) the case of patients experiencing serious medical events because they realize the necessity of receiving recommended medical care irrespective of costsharing requirements.

Magnitude, seniors: unclear.

Magnitude, seniors vs. non-seniors: unclear.

There was mixed evidence that prescription drug cost-sharing mechanisms (copayment, coinsurance, and deductible) had negative effects on seniors' health.

Magnitude, seniors: unclear.

Magnitude, seniors vs. non-seniors: unclear.

Results were overall inconsistent. Clinician reports suggested a high incidence of adverse events (e.g., psychiatric hospital admissions, emergency department visits) immediately following medicare prescription drug plan and adverse effects of prescription drug substitutions for formularyrelated reasons, however, some long-term care providers did not perceive adverse health effects of Part D among residents.

Magnitude, seniors: unclear.

Magnitude, seniors vs. non-seniors: unclear.

Some evidence that drug cost-sharing led to increases in serious adverse events (defined as the first occurrence of acute care hospitalization, long-term care admission, or death; nursing home admission, use of emergency mental health services among those with schizophrenia).

Magnitude, poor/chronically ill: unclear.

Magnitude, poor/chronically ill vs. non-poor/chronically ill: unclear.

Some studies found that higher cost-sharing was associated with adverse outcomes especially among vulnerable populations such as the elderly and poor.

Magnitude, poor/chronically ill: unclear

Magnitude, poor/chronically ill vs. non-poor/chronically ill: unclear.

Low-income people were at greater risk than higher income people in terms of poor health outcomes due to increased cost-sharing.

magnitude, low income: unclear.

magnitude, low income vs high income: unclear.

Adverse health consequences of cost-sharing (unclear if drug cost-sharing only) have been found for patients with congestive heart failure, lipid disorders, diabetes, and schizophrenia.

Magnitude, chronically ill: unclear

Magnitude, chronically ill vs. non-chronically ill: unclear.

Health insurance and lower cost-sharing were associated with hypertension awareness and hypertension control in individuals being treated for hypertension, or, alternatively, measured by the mean blood pressure amongst individuals with hypertension.

Magnitude, individuals with hypertension: unclear.

Magnitude, individuals with hypertension vs. individuals without hypertension: unclear.

Results for clinical outcomes were scarce and mixed (only 2 studies were identified). Magnitude, individuals with cardiovascular-related chronic disease: unclear.

Magnitude, individuals with cardiovascular-related chronic diseases vs. individuals without cardiovascular-related chronic diseases: unclear.

Only 1 included study examined the association between changes in copayments and health outcomes; higher copayments were associated with poorer glycemic control.

Magnitude, individuals with heart failure or diabetes mellitus: each $\$ 5$ increase in patient drug cost share resulted in a $0.1 \%$ point increase in glycosylated hemoglobinA(1c).

Magnitude, individuals with heart failure or diabetes mellitus vs. individuals without heart failure or diabetes mellitus: unclear.

\footnotetext{
a Population examined by each included review
} 
acute myocardial infarction and that this finding did not vary by sex [23].

\section{Associations of prescription drug insurance and cost-sharing with health}

A total of 21 reviews reported on the association between prescription drug insurance or cost-sharing and health outcomes (Tables 2 and 7). Eleven of these reviews explored the association in the general population [19, $23-26,29,30,32,37,39,50]$ of which two focused specifically on the Canadian population $[16,46]$. Six reviews examined health generally $[23,25,26,29,30,46]$, five all-cause mortality $[16,24,37,39,50]$, four self-reported health $[19,32,39,50]$ and one review investigated cardiovascular-related mortality [50], adverse events [32] and vascular events [50].

Overall, there was limited evidence of a clear relationship between prescription drug insurance or cost-sharing and health outcomes. With one exception [32], several older reviews reported that very few empirical studies had examined the association between drug insurance/ cost-sharing and health, and concluded that, on the whole, existing studies provided mixed or unclear evidence $[19,23,25,26,29,30,37]$. More recent reviews (published in 2015 and 2019) tended to conclude that drug insurance and lower cost-sharing were associated with better health. One review found that individuals with drug insurance had better health outcomes than those without, that drug insurance restrictions led to a decline in health status, and that extending drug coverage yielded mixed results [39]. Another review found that in all included studies, there was an inverse association between higher drug cost-sharing and health outcomes such as self-assessed health, major vascular events, cardiovascular-related mortality and all-cause mortality [50]. The above conclusions were, however, all based on very few primary studies.

\section{Differences between subgroups: SES, health status, age and sex/gender}

Reviews highlighted a paucity of studies that examined the associations of prescription drug insurance and costsharing with health among the poor and the chronically ill (Tables 2 and 8). Two older reviews found some evidence that drug cost-sharing was associated with adverse health outcomes in lower-income populations and another suggested that low-income individuals were at greater risk of poor health outcomes due to increased cost-sharing than higher-income individuals $[17,23$, 29]. Three of four reviews that specifically discussed the chronically ill found that cost-sharing was associated with adverse health outcomes in patients with heart disease, hypertension, lipid disorders, and diabetes [30, 34, 45].
Two of the three reviews, however, discussed the association between health insurance generally (i.e., including but not limited to drug insurance) and health outcomes $[30,34]$. One review found no evidence of an association between drug cost-sharing and clinical outcomes among patients with cardiovascular-related chronic disease [38]. Four older reviews specifically focused on the association between insurance and cost-sharing and health among seniors $[15,18,20,35]$. Two reviews reported mixed findings $[20,35]$ while two reviews reported that higher cost-sharing was associated with worse health outcomes, including higher mortality and morbidity among seniors $[15,18]$. One review pointed out that this association did not remain when there were generous provisions in place to protect vulnerable populations from incurring undue financial risk as a result of cost-sharing [18]. However, similar to previous reported outcomes, no comparisons were drawn between the poor and non-poor, the chronically ill and non-chronically ill, and the elderly and nonelderly and how health outcomes may have differed between them. We did not identify a single review that discussed potential differences between sex/gender in the association of prescription drug insurance and cost-sharing with health.

\section{Risk of bias assessment}

In our umbrella review, we found that the most common limitations were the lack of an a priori study design and issues with clarity in reporting search strategies and results. Reviews often did not clearly report data screening and extraction procedures including exclusion and inclusion criteria, had poorly described search strategies or non-systematic search strategies, failed to provide or clearly synthesize study characteristics and, most often than not, did not provide a list of excluded studies. The most important limitation was, however, the lack of attention given to quality assessments. About half of the included reviews did not conduct any formal quality assessments and many that did often failed to appropriately describe and justify their quality assessment.

\section{Discussion \\ Main findings}

We found consistent evidence that changes in drug costsharing and/or drug insurance were associated with drug use. Lower cost-sharing and having drug insurance were associated with increased drug use while higher drug cost-sharing and the lack or loss of drug insurance were associated with decreased drug use. We also found consistent evidence that the poor, the chronically ill, seniors and children were similarly responsive to changes in insurance and cost-sharing. Although the direction of the associations between changes in drug insurance and 
cost-sharing was clear, the magnitude of these associations was difficult to ascertain. The demand for prescription drugs is most certainly inelastic (i.e., a percentage change in price is associated with a smaller percentage change in demand) with an own-price elasticity ranging from about -0.2 to -0.6 , depending on drug class, intervention, disease, and population studied. We found that lower drug cost-sharing and drug insurance were associated with lower healthcare services utilization including emergency room visits, hospitalizations, and outpatient visits. Similar results were found in all population subgroups aside from children, although the literature on the poor and children was very limited. We did not find consistent evidence of an association between cost-sharing and insurance and health. While several reviews reported mixed or no evidence, more recent reviews tended to conclude that there was some evidence that increased cost-sharing led to poorer health outcomes because of reduced drug adherence. Again, the magnitude of effect was unclear and evidence on the elderly, chronically, ill, and poor was limited and mixed. Lastly, we did not find any evidence that the association between drug insurance or cost-sharing and drug use, health services use, or health differed by SES, health status, age or sex.

We found two reviews that specifically studied the Canadian population. An older review examined Canadian evidence of the effects of cost-sharing mechanisms of provincial drug benefit programs on drug utilization and health [16]. A more recent scoping review examined the extent, determinants, and consequences of cost-related nonadherence to prescription medications in Canada [46]. The two reviews generally found that higher drug cost-sharing reduced drug use. There was, however, little discussion of the magnitude of associations or subgroup differences in price responsiveness [16, 46]. The review of cost-related nonadherence to prescription medications found limited and mixed evidence that cost-sharing increased health services use [46]. A more recent review examined the prevalence, predictors, and clinical impact of cost-related medication nonadherence in Canada [52]. Along with lower income, younger age, and poorer health, high out-of-pocket spending and drug insurance were found to be associated with medication cost-related nonadherence [52].

\section{Limitations}

Our review has some inherent limitations. Although we identified 38 relevant reviews, this does not equate to 38 independent reviews because there was considerable overlap between the studies that were included in the reviews. Although we are confident about the direction of the associations we examined, we had difficulties commenting on the precise magnitude of associations as these were often not clearly identified and reported in the reviews themselves, and could not be easily extracted and synthesized. Lastly, our review did not examine reviews that focused specifically on an alternative cost-sharing design called "value-based cost-sharing" or more generally "value-based insurance design." The key feature of value-based insurance design is to link the amount of cost-sharing across services with the documented effectiveness and cost-effectiveness of a service, drug or device. A list of reviews that focused specifically on value-based designs is provided in the Additional file 1.

\section{Implications for research}

Our umbrella review highlights a paucity of research focused on children and youth. We identified no reviews that specifically focused on children and youth. The reviews we included generally sparingly discussed the potential impact of drug insurance and cost-sharing among youth. In our search, we identified a single review that focused specifically on children, which we excluded because it focused primarily on access and not on drug use. Unger and Ariely, identified two studies that compared insured and uninsured paediatric populations which showed increased access to healthcare services and medications for insured children [53]. The review noted that access to prescription drugs frequently differed by the type of health insurance provider and the type of cost-sharing arrangement and that more research was needed. The lack of discussion of potential sex/gender differences in the associations of prescription drug insurance and cost-sharing with drug use, health services use, and health is of concern. Only two reviews discussed this issue and reported on just two primary studies. It is unclear if the lack of discussion of potential sex/gender differences is due to reviews or primary studies not investigating it.

Future reviews need to give more consideration to appropriately synthesizing and discussing magnitudes of effect for given associations as solely presenting the direction or significance of a relationship provides minimal information. A stronger emphasis also needs to be placed on improving the methodological rigour of reviews by employing systematic and transparent methods to develop and execute search strategies as well as conducting quality assessment that is applicable to the literature being reviewed and ensuring that it is adequately discussed. Lastly, our umbrella review highlights the importance of searching systematically both peerreviewed and grey literature, and not to overly rely on a single repository of research evidence. For example, only 11 reviews are included in Health Systems Evidence, which is perhaps the most comprehensive repository of reviews relevant to health systems. 


\section{Conclusions}

\section{Implications for health equity}

Socioeconomic, racial and ethnic inequities in health care and drug coverage are well documented in the US and Canada [1, 54, 55]. For example, in 2015-16 in Canada, relative to adults in the lowest income decile, those in the 10th decile had odds of reporting drug insurance coverage that were more than five times higher [54]. In the US, Black and Latinx/Hispanic adults have historically reported substantially higher uninsured rates than white adults. In 2019, while the uninsured rate among white adults was only $9 \%$, the uninsured rates among Black and Latinx/Hispanic adults stood at 14 and 26\%, respectively. Consequently, universal pharmacare would likely increase drug use among lower-income populations relative to higher-income populations, and potentially reduce health inequities.

\section{Implications for policy}

Although cost-sharing can be used as a mechanism to reduce pharmaceutical expenditures, the associated impacts on health service use may offset those benefits. These cross-price effects of extending drug coverage are, however, often ignored in costing simulation, [56, 57] and need to be taken into consideration by policymakers. Lastly, current Canadian universal pharmacare proposed designs most often include cost-sharing for all but the most vulnerable despite evidence that cost-sharing reduces drug use and treatment adherence, and likely results in increases in health services use $[3,58]$.

\section{Abbreviations \\ ACEl: Angiotensin-converting enzyme inhibitors; AMSTAR: Assessment of Mul- tiple Systematic Reviews; ARB: Angiotensin-receptor blockers; Cl: Confidence Intervals; ED: Emergency Department; EPHPP: Effective Public Health Practice Project; EPOC: Effective Practice and Organisation of Care; GRADE: Grading of Recommendations, Assessment, Development and Evaluations; HR: Hazard Ratio; ITS: Interrupted Time Series; NIH: National Institute of Health; OR: Odds Ratio; RCT: Randomized Controlled Trial; RePEc: Research Papers in Economics; RM: Repeated Measures; RR: Relative Risk; SES: Socioeconomic Status; STROBE: Strengthening the Reporting of Observational Studies in Epidemiology; US: United States.}

\section{Supplementary Information}

The online version contains supplementary material available at https://doi. org/10.1186/s12913-022-07554-w.

Additional file 1: Appendix A. Search strategy. Appendix B. Quality Assessment / Risk of Bias tools. Appendix C. Characteristics of included studies. Appendix D. Excluded studies. Appendix E. List of Canadian studies included in reviews. Appendix F. List of reviews that focused specifically on value-based cost-sharing/insurance design.

Acknowledgements

We thank our collaborator Carley Hay from the Ontario Ministry of Health, Umaima Abbas, Bria Barton, Gioia Buckley, Selene Miller, Erica Stone and Riya
Trivedi for their research assistance, and Arthur Sweetman and Jeremiah Hurley for their comments and discussion.

\section{Authors' contributions}

GEG conceptualized the study. SG and GEG designed the search strategy. GEG, TF, SG, and KK assessed studies for inclusion, extracted detailed study characteristics, identified study limitations, and contributed to the interpretation of the findings. GEG and TF led the writing of the article. SG and KK revised the article critically for important intellectual content. GEG obtained funding. The authors read and approved the final manuscript.

\section{Funding}

Canadian Institutes for Health Research (grant \# 378730). GEG holds the Centre for Health Economics and Policy Analysis (CHEPA)/Ontario Ministry of Health and Long-Term Care (MOHLTC) Chair in Health Equity, an endowed Chair funded in part by the MOHLTC. The funders had no role in the study design, analysis, interpretation, writing of the report, or in the decision to submit this article for publication.

Availability of data and materials

All data generated or analyzed during this study are included in this published article [and its supplementary information files].

\section{Declarations}

Ethics approval and consent to participate

Institutional review board approval was not needed because we reviewed and synthesized existing research.

\section{Consent for publication}

We confirm that all contributors agreed to submit this paper for publication.

\section{Competing interests}

None.

\section{Author details}

${ }^{1}$ Centre for Health Economics and Policy Analysis, McMaster University, Room 229, 1280 Main Street West, Hamilton, ON L8S 4K1, Canada. ${ }^{2}$ Department of Health Research Methods, Evidence, and Impact, McMaster University, Hamilton, ON, Canada. ${ }^{3}$ Department of Economics, McMaster University, Hamilton, ON, Canada.

Received: 30 August 2021 Accepted: 27 January 2022

Published online: 03 March 2022

\section{References}

1. Sommers BD. Health insurance coverage: what comes after the ACA? Health Aff (Millwood). 2020;39(3):502-8.

2. Rosenthal MB. The growing problem of out-of-pocket costs and affordability in employer-sponsored insurance. JAMA. 2021;326(4):305-6.

3. Health Canada. A prescription for Canada: achieving pharmacare for all. Final report of the Advisory Council on the Implementation of National Pharmacare. Ottawa: Government of Canada; 2019.

4. Marchildon GP. Canada: health system review. Copenhagen: WHO Regional Office for Europe on behalf of the European Observatory on Health Systems and Policies; 2013

5. OECD. Health at a glance 2019: OECD indicators. Paris: Organization for Economic Cooperation and Development; 2019.

6. Newhouse JP, The Insurance Experiment G. Free for all? Lessons from the RAND health insurance experiment: a RAND study. Cambridge and London: Harvard University Press; 1993.

7. Park YJ, Martin EG. Medicare part D's effects on drug utilization and out-of-pocket costs: a systematic review. Health Serv Res. 2017;52(5):1685-728.

8. Glied SA, Collins SR, Lin S. Did the ACA lower Americans'financial barriers to health care? Health Aff (Millwood). 2020:39(3):379-86.

9. Morgan S, Coombes M. Income-based drug coverage in British Columbia: towards an understanding of the policy. Healthc Policy. 2006;2(2):92-108. 
10. Morgan SG, Gagnon M-A, Charbonneau M, Vadeboncoeur A. Evaluating the effects of Quebec's private-public drug insurance system. CMAJ. 2017;189(40):E1259-E63.

11. Shea BJ, Reeves BC, Wells G, et al. AMSTAR 2: a critical appraisal tool for systematic reviews that include randomised or non-randomised studies of healthcare interventions, or both. BMJ. 2017;358:j4008.

12. Greenland $\mathrm{S}, \mathrm{O}^{\prime}$ Rourke K. On the bias produced by quality scores in meta-analysis, and a hierarchical view of proposed solutions. Biostatistics. 2001:2(4):463-71.

13. Lundh A, Gotzsche PC. Recommendations by Cochrane review groups for assessment of the risk of bias in studies. BMC Med Res Methodol. 2008;8:22.

14. Higgins J, Thomas J, Chandler J, et al. Cochrane handbook for systematic reviews of Interventions version 6.0 (updated July 2019): Cochrane; 2019. Available from www.training.cochrane.org/handbook

15. Adams AS, Soumerai SB, Ross-Degnan D. The case for a medicare drug coverage benefit: a critical review of the empirical evidence. Annu Rev Public Health. 2001;22:49-61.

16. Harten C, Ballantyne P. The impact of cost-sharing within Canadian provincial drug benefit programs: a review. J Pharm Finance Econ Policy. 2004;13(1):35-53.

17. Lexchin J, Grootendorst P. Effects of prescription drug user fees on drug and health services use and on health status in vulnerable populations: a systematic review of the evidence. Int J Health Serv. 2004;34(1):101-22.

18. Rice T, Matsuoka KY. The impact of cost-sharing on appropriate utilization and health status: a review of the literature on seniors. Med Care Res Rev. 2004:61(4):415-52.

19. Gibson TB, Ozminkowski RJ, Goetzel RZ. The effects of prescription drug cost sharing: a review of the evidence. Am J Manag Care. 2005;11(11):730-40

20. Maio V, Pizzi L, Roumm AR, et al. Pharmacy utilization and the Medicare modernization act. Milbank Q. 2005;83(1):101-30.

21. Briesacher BA, Gurwitz JH, Soumerai SB. Patients at-risk for cost-related medication nonadherence: a review of the literature. J Gen Intern Med. 2007;22(6):864-71.

22. Gemmill MC, Costa-Font J, McGuire A. In search of a corrected prescription drug elasticity estimate: a meta-regression approach. Health Econ. 2007;16(6):627-43.

23. Goldman DP, Joyce GF, Zheng Y. Prescription drug cost sharing: associations with medication and medical utilization and spending and health. JAMA. 2007;298(1):61-9.

24. Gemmill MC, Thomson S, Mossialos E. What impact do prescription drug charges have on efficiency and equity? Evidence from high-income countries. Int J Equity Health. 2008;7:12.

25. Remler DK, Greene J. Cost-sharing: a blunt instrument. Annu Rev Public Health. 2009:30:293-311.

26. Green CJ, Maclure M, Fortin PM, Ramsay CR, Aaserud M, Bardal S. Pharmaceutical policies: effects of restrictions on reimbursement. Cochrane Database Syst Rev. 2010;(8):CD008654. https://doi.org/10.1002/14651858. CD008654.

27. Holst J. Patient cost sharing: reforms without evidence, Theoretical considerations and empirical findings from industrialized countries, WZB discussion paper, no. SP I 2010-303. Berlin: Wissenschaftszentrum Berlin für Sozialforschung (WZB); 2010 .

28. Polinski JM, Kilabuk E, Schneeweiss S, Brennan T, Shrank WH. Changes in drug use and out-of-pocket costs associated with Medicare part D implementation: a systematic review. J Am Geriatr Soc. 2010;58(9):1764-79.

29. Swartz K. Cost-sharing: effects on spending and outcomes. The synthesis project. Research synthesis report no. 20. Princeton: Robert Wood Johnson Foundation; 2010

30. Baicker K, Goldman D. Patient cost-sharing and healthcare spending growth. J Econ Perspect. 2011;25(2):47-68.

31. Polinski JM, Donohue JM, Kilabuk E, Shrank WH. Medicare part D's effect on the under- and overuse of medications: a systematic review. J Am Geriatr Soc. 2011;59(10):1922-33.

32. Eaddy MT, Cook CL, O'Day K, Burch SP, Cantrell CR. How patient costsharing trends affect adherence and outcomes: a literature review. PT. 2012;37(1):45-55

33. Lemstra M, Blackburn D, Crawley A, Fung R. Proportion and risk indicators of nonadherence to statin therapy: a meta-analysis. Can J Cardiol. 2012;28(5):574-80.
34. Maimaris W, Paty J, Perel P, et al. The influence of health systems on hypertension awareness, treatment, and control: a systematic literature review. PLoS Med. 2013;10(7):e1001490.

35. Pimentel CB, Lapane KL, Briesacher BA. Medicare part D and long-term care: a systematic review of quantitative and qualitative evidence. Drugs Aging. 2013;30(9):701-20.

36. Sinnott S-J, Buckley C, O'Riordan D, Bradley C, Whelton $\mathrm{H}$. The effect of copayments for prescriptions on adherence to prescription medicines in publicly insured populations; a systematic review and meta-analysis. PLoS One. 2013;8(5):e64914.

37. Kiil A, Houlberg K. How does copayment for health care services affect demand, health and redistribution? A systematic review of the empirical evidence from 1990 to 2011. Eur J Health Econ. 2014;15(8):813-28.

38. Mann BS, Barnieh L, Tang K, et al. Association between drug insurance cost sharing strategies and outcomes in patients with chronic diseases: a systematic review. PLoS One. 2014;9(3):e89168.

39. Kesselheim AS, Huybrechts KF, Choudhry NK, et al. Prescription drug insurance coverage and patient health outcomes: a systematic review. Am J Public Health. 2015;105(2):E17-30.

40. Luiza VL, Chaves LA, Silva RM, et al. Pharmaceutical policies: effects of cap and co-payment on rational use of medicines. Cochrane Database Syst Rev. 2015;5:CD007017.

41. Aziz H, Hatah E, Makmor Bakry M, Islahudin F. How payment scheme affects patients' adherence to medications? A systematic review. Patient Prefer Adherence. 2016;10:837-50.

42. Banerjee A, Khandelwal S, Nambiar L, et al. Health system barriers and facilitators to medication adherence for the secondary prevention of cardiovascular disease: a systematic review. Open Heart. 2016;3(2):e000438.

43. Doshi JA, Li P, Ladage VP, Pettit AR, Taylor EA. Impact of cost sharing on specialty drug utilization and outcomes: a review of the evidence and future directions. Am J Manag Care. 2016;22(3):188-97.

44. Powell V, Saloner B, Sabik LM. Cost sharing in Medicaid: assumptions, evidence, and future directions. Med Care Res Rev. 2016;73(4):383-409.

45. Gourzoulidis G, Kourlaba G, Stafylas P, Giamouzis G, Parissis J, Maniadakis N. Association between copayment, medication adherence and outcomes in the management of patients with diabetes and heart failure. Health Policy. 2017;121(4):363-77.

46. Gupta S, McColl MA, Guilcher SJ, Smith K. Cost-related nonadherence to prescription medications in Canada: a scoping review. Patient Prefer Adherence. 2018;12:1699-715.

47. Ofori-Asenso R, Jakhu A, Curtis AJ, et al. A systematic review and metaanalysis of the factors associated with nonadherence and discontinuation of statins among people aged $\geq 65$ years. J Gerontol A Biol Sci Med Sci. 2018;73(6):798-805.

48. Schneider APH, Gaedke MA, Garcez A, Barcellos NT, Paniz VMV. Effect of characteristics of pharmacotherapy on non-adherence in chronic cardiovascular disease: a systematic review and meta-analysis of observational studies. Int J Clin Pract. 2018;72(1). https://doi.org/10.1111/ijcp.13044.

49. Cheen MHH, Tan YZ, Oh LF, Wee HL, Thumboo J. Prevalence of and factors associated with primary medication non-adherence in chronic disease: a systematic review and meta-analysis. Int J Clin Pract. 2019:73(6):e13350

50. Kolasa K, Kowalczyk M. The effects of payments for pharmaceuticals: a systematic literature review. Health Econ Policy Law. 2019;14(3):337-54.

51. Mishuk AU, Fasina I, Qian J. Impact of U.S. federal and state generic drug policies on drug use, spending, and patient outcomes - a systematic review. Res Soc Adm Pharm. 2020;16(6):736-45. https://doi.org/10.1016/j. sapharm.2019.08.031

52. Holbrook AM, Wang M, Lee M, et al. Cost-related medication nonadherence in Canada: a systematic review of prevalence, predictors, and clinical impact. Syst Rev. 2021;10(1):11.

53. Ungar WJ, Ariely R. Health insurance, access to prescription medicines and health outcomes in children. Expert Rev Pharmacoecon Outcomes Res. 2005;5(2):215-25.

54. Guo EX, Sweetman A, Guindon GE. Socioeconomic differences in prescription drug supplemental coverage in Canada: a repeated crosssectional study. Health Policy. 2020;124(3):252-60.

55. Baumgartner JC, Collins SR, Radley DC. Racial and ethnic inequities in health care coverage and access, 2013-2019. Data brief, June 2021. New York: Commonwealth Fund; 2021. 
56. Morgan SG, Law M, Daw JR, Abraham L, Martin D. Estimated cost of universal public coverage of prescription drugs in Canada. CMAJ. 2015;187(7):491-7.

57. Office of the Parliamentary Budget Officer. Federal cost of a national pharmacare program. Ottawa: Parliamentary Budget Officer (PBO); 2017.

58. Yeung K, Morgan SG. Should national pharmacare apply a value-based insurance design? CMAJ. 2019;191(29):E811-E5.

\section{Publisher's Note}

Springer Nature remains neutral with regard to jurisdictional claims in published maps and institutional affiliations.

- fast, convenient online submission

- thorough peer review by experienced researchers in your field

- rapid publication on acceptance

- support for research data, including large and complex data types

- gold Open Access which fosters wider collaboration and increased citations

- maximum visibility for your research: over $100 \mathrm{M}$ website views per year

At BMC, research is always in progress.

Learn more biomedcentral.com/submissions 